\title{
Structural Change, Engel's Consumption Cycles AND KaLDOR's FaCts of ECONOMIC GROWTH
}

\author{
Reto Foellmi, University of Zurich Josef Zweimüller, University of Zurich*
}

December 20, 2005

\begin{abstract}
The model presented in this paper reconciles two of the most important features of the long-run growth process: the massive changes in the structure of production and employment; and the Kaldor facts of economic growth. Structural change occurs because Engel-curves are non-linear. Each new good goes through Engel's consumption cycle, i.e. starts out as a luxury with a high income elasticity and ends up as a necessity with a low income elasticity. The coexistence of stagnating and expanding industries imply a changing sectoral composition and a continuous reallocation of labor across sectors. Nonetheless macroeconomic aggregates grow at a constant rate, and the real interest rate and the labor share are constant. Our model also addresses the two-way causality between economic growth and structural change. Complementarities between aggregate and sectoral growth may give rise to multiple equilibria providing a possible explanation for development failures.
\end{abstract}

JEL classification: O40, O11, O31, D91, L16

Keywords: Kaldor facts, Engel-curve, structural change, structural transformation, hierarchic preferences, demand externalities, multiple equilibria.

${ }^{*}$ University of Zurich, Institute for Empirical Research in Economics, Bluemlisalpstrasse 10, CH- 8006 Zürich, Tel: ++41-1-634 37 26, Fax: ++41-1-634 49 07, e-mail: foellmi@iew.unizh.ch and zweim@iew.unizh.ch. Josef Zweimüller is also associated with CEPR, IZA and CESifo. 


\section{Introduction}

The process of economic development is characterized by fundamental changes in the structure of production and employment. In a historical perspective, the emergence of new and the decline of old industries has led to a dramatic reallocation of resources between sectors of production. ${ }^{1}$ Despite of these large structural changes, the long-term growth process has been remarkably stable in the aggregate. As mentioned by Kaldor (1961) in his famous stylized facts, a situation where the growth rate, interest rate, capital output ratio, and labor share are constant over time is a reasonable approximation of the long-run growth experience of a modern economy.

Changes in the structure of production and employment result either from sectoral differences in productivity growth or from sectoral differences in income elasticities of demand. This paper focuses on the demand side. Our starting point is the basic idea that consumption expands along a hierarchy of needs and wants. This idea goes at least back to Plato and has played an important role in the thinking of classical economists. The German statistician Ernst Engel (1857) pioneered the empirical analysis of consumption patterns. Engel's law the falling budget share for food with rising incomes - has become one the most robust empirical findings in economics (Houthakker, 1987). But Engel (1857) himself believed in a more general law of consumption and formulated a theory of a equilibrium structure of production and employment based on a hierarchy of wants. ${ }^{2}$ This view has been supported by many later writers. For instance, Kindleberger $(1989$, p. 9) argues

"Engel's law applies to more than food, it is a general law of consumption. (...)

A given item may go through the Engel's consumption cycle of a luxury, with high income elasticity, to a necessity with low income elasticity."

Modern growth theory has been surprisingly silent on the issue of how to reconcile the

\footnotetext{
${ }^{1}$ Maddison (1987) documents the huge reallocation of labor in six major industrialized countries (France, Germany, Japan, Netherlands, U.K. and U.S.). His data show that the average employment share in agriculture was as high as $46.0 \%$ in 1870 and has decreased to $5.5 \%$ by 1984 . During the same period the average employment share in the service sector has increased from $26.4 \%$ to $62.2 \%$.

${ }^{2}$ Engel (1857) concluded explicitely from his empirical analysis that needs have a hierarchic structure: "Nunmehr (ist) gleichsam eine Scala der Bedürfnisse des Lebens zu Tage gefördert (p. 27)."The idea that, in the age of mass consumption, the very concept of necessities and luxuries has changed, has been stressed by Katona (1964). See also the discussion on Engel-curves in Pasinetti (1981, Chapter IV).
} 
huge structural changes with the Kaldor facts of economic growth. The first paper that has explicitly addressed the issue is Kongsamut, Rebelo, and Xie (2001). They study a three-sector model where consumers have Stone-Geary preferences over an agricultural good (a necessity), a manufactured good (with an income-elasticity near unity), and services (a luxury). They find that a "generalized balanced growth path", along which the Kaldor facts are satisfied, is only possible if preference and technology parameters jointly satisfy a knife-edge condition. Just like in Kongsamut et al. (2001), in our model structural change is driven by sectoral differences in income elasticities. Unlike Kongsamut et al. (2001), however, our model studies a continuum of products and reconciles structural change and the Kaldor facts without putting joint restrictions on technology and preference parameters.

To the best of our knowledge, other papers rationalizing structural change and steady growth in a unified framework have focused exclusively on technological differences across sectors. In Ngai and Pissarides (2005) sectors experience different total factor productivity growth rates (but have identical capital-intensities). They show that the aggregate growth process satisfies the Kaldor facts if the intertemporal utility function is logarithmic in the consumption composite; and the consumption composite is non-logarithmic (yet homothetic) across goods. Another recent paper by Acemoglu and Guerrieri (2005) does not only allow for different rates of technical progress but also for differences in capital intensities across sectors. In a two-sector growth model with constant elasticity of substitution preferences and Cobb-Douglas production technologies they show that, provided the elasticity of substitution is less than one, convergence to the limiting equilibrium may be slow and along the transition path (when the sectoral structure changes) the capital share and the interest rate vary only by relatively small amounts hence reconciling structural change with the Kaldor facts. ${ }^{3}$

\footnotetext{
${ }^{3}$ Starting with Baumol (1967) an important strand of the literature views structural change as a supply phenomenon. Sectors with low technical progress suffer from the "cost disease", i.e. rising relative costs and prices. When relative output levels of stagnant and dynamic sectors remain roughly constant (due to limited substitutability between products), the Kaldor facts are necessarily violated. Recently other authors have studied models where relative productivity between the agricultural and the manufacturing sectors determine patterns of the structural transformation without accounting for the Kaldor facts. See Hansen and Presott (2002), Parente and Prescott (2004). See also the endogenous growth models by Young (1993a, 1993b) where changes in the structure of production arising from sector-specific learning-by-doing and/or complementarities among old and new technologies; by Chari and Hopenhayn (1991) where asymmetries arise from lags in the diffusion of new technologies; and by Thompson (2001) where quality uncertainty in connection with rising
} 
In contrast to these technology-based approaches, our model relies on Engel's consumption cycles to account for structural change. In this framework the fundamental cause of structural change is the hierarchic nature of wants. ${ }^{4}$ During the process of economic growth, consumers get saturated with existing products. In order to sustain growth new goods (covering new wants) have to be continuously introduced. To highlight the demand-channel and to keep things simple we abstract from technological differences across sectors. However, we discuss in a separate section how various dimensions of technological heterogeneity can be incorporated in our model without substantially changing our main message.

Our analysis leads to the following results. First, the hierarchic nature of demand implies that structural change takes the form of a reallocation of resources from old to new industries. At any given date old industries supply necessities and new industries supply luxuries. These sectors experience different growth rates of demand and a reallocation of resources is necessary to satisfy these demands. The Engel-curve of a typical good is non-linear: demand is zero at very low income levels, becomes positive when a critical income level has been surpassed and approaches a saturation point when incomes grow large. As an implication, a product's income elasticity is initially high and gradually decreases with growing income. In other words, each good starts off as a luxury with a high income elasticity and ends up as a necessity with a low income elasticity. Hence our model formalizes the Engel-Kindleberger idea of consumption cycles.

Second, along the long-run growth path the Kaldor facts are satisfied. Prima facie reconciling non-linear Engel-curves and the Kaldor facts seems to be non-trivial. However, just as a constant elasticity of intertemporal substitution is required for steady growth in a one-good economy, a constant intertemporal substitution elasticity of total consumption expenditures is required in our framework where there are many goods. along the balanced growth path total consumption expenditures grow at the same rate as total output. However, along this path the level of demand for a particular product does not grow at the economy-wide growth rate.

product variety leads to a non-degenerate firm size distribution. In these models, the demand-side plays a passive role as preferences between the various goods are assumed to be symmetric.

${ }^{4} \mathrm{~A}$ related literature has studied the implications of non-homothetic preferences and non-linear Engel curves for structural change in models that do not account for the Kaldor facts (e.g. Matsuyama, 1992, 2002, Echevarria, 1997, Laitner, 2000, Caselli and Coleman, 2001, Gollin, Parente, and Rogerson, 2002, 2004, Greenwood and Uysal, 2005). For an overview on recent theories of structural change see Matsuyama (2005). 
New goods experience a higher increase in demand than old goods involving a transfer of labor resources from old to new industries. By featuring a steady growth path our analysis provides a natural extension of the one-sector growth model to a multi-sector set-up in which preferences over the various goods have a hierarchical structure.

Third, the evolution of consumption along a hierarchy of wants highlights the importance of product innovations for sustaining growth. When consumers get satiated with existing products, demand for the satisfaction of new wants arises. New goods have to be continuously introduced to ensure that demand keeps pace with technical progress. When growth is driven by such innovations, an important two-way causality between growth and structural change arises. On the one hand, the aggregate growth rate depends on structural change because innovation incentives are crucially determined by the growth rates in the new industries. On the other hand, the speed of structural change is itself determined by aggregate growth. To highlight this interdependence between growth and structural change, we present our model in the context of a standard endogenous growth framework a la Romer (1990) and Grossman and Helpman (1992). In this context, we show that the above complementarities between sectoral and aggregate growth may give rise to multiple equilibria: When innovators expect a disproportionate increase in demand for new products, incentives to innovate are strong and vice versa. Expectations are self-fulfilling as high sectoral growth requires high aggregate growth which can only be sustained in an innovative environment.

Fourth, though the main purpose of the paper is theoretical, we provide a simple quantitative exercise to confront our model with historical data for the U.S. and other industrialized countries. We interpret our model in the context of the sectoral trichotomy (agriculture, manufacturing, services) by assuming that the most urgent wants are satisfied by agricultural goods, the less urgent ones by manufactures and the most luxurious ones by services. We show that our model fits the data quite well. In particular, the model predicts a movement of labor out of agriculture of an order of magnitude that is observed in OECD data. The model also predicts an the evolution of the manufacturing labor share follows an inverse U: the manufacturing labor share increases in earlier stages of development and declines in later stages which is also in line with the experience in most OECD countries.

The paper is organized as follows. In Section 2 we present the general set-up of the model, solve the static problem of consumers and firms, and discuss the resulting structures of demand 
and prices. Section 3 outlines our assumptions on technical progress, the innovation incentives of firms, and the optimal allocation of expenditures by consumers. Section 4 characterizes the conditions under which a unique equilibrium growth path exists. In Section 5 we discuss the co-existence of structural change and the Kaldor facts. Section 6 provides a discussion of the possibility of multiple equilibria. In Section 7 we look in some detail at the robustness of our results with respect to the basic assumptions, in particular, heterogeneity in technologies across sectors. Section 8 calibrates our model to data of six industrialized countries. Section 9 concludes and discusses directions for future research.

\section{The Static Equilibrium}

\subsection{Preferences and consumer demand}

Consider a representative agent economy with infinitely many potentially producible goods ranked by an index $i$. We study the structure of consumption that is generated by preferences of the form

$$
u(\{c(i)\})=\int_{0}^{\infty} \xi(i) v(c(i)) d i
$$

where $v(c(i))$ is an indicator for the utility derived from consuming good $i$ in quantity $c$. The 'baseline' utility $v(c(i))$ satisfies the usual assumptions $v^{\prime}>0$ and $v^{\prime \prime}<0$; and the 'hierarchy' function $\xi(i)$ is monotonically decreasing in $i, \xi^{\prime}(i)<0$, hence low- $i$ goods get a higher weight than high- $i$ goods.

A meaningful specification of hierarchic preferences has to take account of two facts. First, some goods may not be consumed because the consumer cannot afford them. This implies that preferences must be such that the non-negativity constraints may become binding and Engel-curves for the various goods are non-linear. Formally, binding non-negativity constraints require that the marginal utility of consuming good $i$ in quantity zero, $\xi(i) v^{\prime}(0)$ is finite for all $i>0$. If marginal utility at quantity zero were infinitely large, it would always be optimal to consume a (small) positive amount even when prices are very high and/or the budget is very low. ${ }^{5}$

\footnotetext{
${ }^{5}$ Non-negativity constraints never become binding in the standard monopolistic competition model (Dixit and Stiglitz (1978)) that dominates the macroeconomic literature. In that model $v(c(i))=\frac{1}{\alpha} c(i)^{\alpha}, \alpha<1$, and $v^{\prime}(0)=\infty$. Thus in the standard monopolistic competition model all available goods are consumed in positive
} 
Second, the generalized version of Engel's law implies that additional income is spent primarily on low-priority goods (high income elasticity). This feature is caught by the formulation that the utility of consumption of different goods differs only in the factor $\xi(i)$. As the hierarchy function $\xi(i)$ is decreasing in $i$ the marginal utility of a high priority good (low $i$ ) falls quickly. Optimal consumer behavior implies that additional income is spent primarily on the low-priority goods with slowly falling marginal utilities.

To keep the analysis tractable we make two assumptions concerning the functional forms of the weighting function $\xi(i)$ and the baseline utility $v(c(i))$. First we assume that the weighting function is a power function $\xi(i)=i^{-\gamma}$ with $\gamma \in(0,1)$. Second, we assume that the baseline utility is quadratic, $v(c(i))=\frac{1}{2}\left[s^{2}-(s-c(i))^{2}\right]$. This specification allows for binding nonnegativity constraints as marginal utility at quantity zero is finite, $\xi(i) v^{\prime}(0)=i^{-\gamma} \frac{1}{2} s^{2}<\infty$, for all goods $i>0$. The first assumption is essential for a dynamic equilibrium featuring the Kaldor facts and to a CRRA utility in the one-good growth model. We will see that, just as the CRRA-form is required to generate balanced growth in the one-good growth model, the weighting function $\xi(i)=i^{-\gamma}$ is required for steady growth with many, hierarchically ordered goods. The second assumption, however, is not essential. While the quadratic subutility function allows for explicit solutions (and binding non-negativity constraints), it can be shown that our analysis holds for any other subutility function (see Foellmi, 2003). In Section 8 we discuss these conditions in more detail. ${ }^{6}$

With these assumptions, we can now specify the objective function of the consumer's static maximization problem. Assume that only goods with high priority $i \in[0, N]$ are available on the market, whereas all $i>N$ have not yet been invented. In that case the consumers'

amounts.

${ }^{6}$ In this sense, our formulation of preferences provides a natural extension of the one-sector framework to a framework with hierachic preferences. In particular, our formulation does not require any link between preference and technology parameters, as in previous attempts to reconcile structural changes with the Kaldor facts. 
objective function is ${ }^{7}$

$$
u(\{c(i)\})=\int_{0}^{\infty} i^{-\gamma} \frac{1}{2}\left[s^{2}-(s-c(i))^{2}\right] d i .
$$

which will be maximized subject to the budget constraint $\int_{0}^{\infty} p(i) c(i) d i=E$ and the nonnegativity constraints $c(i) \geq 0$ for all $i$. The optimality conditions require that the above constraints and the first order conditions

$$
\begin{aligned}
c(i)\left[i^{-\gamma}(s-c(i))-\lambda p(i)\right] & =0 & \forall i \\
i^{-\gamma}(s-c(i))-\lambda p(i) & \leq 0 & \forall i .
\end{aligned}
$$

be satisfied, where $\lambda$ denotes the Lagrangian multiplier.

\subsection{Prices}

We assume there are constant marginal cost in production, equal for all goods, and we normalize these marginal costs to unity. Goods $i \in[0, a N]$ are supplied on competitive markets and goods $i \in(a N, N]$ are supplied by monopolistic firms. This means that high priority (low- $i$ ) goods are supplied by competitive producers and low priority (high- $i$ ) goods are supplied by monopolists. ${ }^{8}$

The prices for goods in the interval $i \in[0, a N]$ are equal to marginal costs which are unity. Determining the prices for the goods $i \in(a N, N]$ is less trivial but straightforward. The market demand function is given by the representative household's optimality conditions (2). The price that the monopolist charges maximizes the objective function $\pi(p(i))=$

\footnotetext{
${ }^{7} v(c(i))=\frac{1}{2}\left[s^{2}-(s-c(i))^{2}\right]$ has been normalized such that $v(0)=0$. This normalization is necessary to prevent divergence of the utility integral because the consumer's preferences are defined over an infinite number of goods. Since only goods in the interval $i \in[0, N]$ can be consumed in positive amounts the consumer's objective can be written as $u(\{c\})=\int_{0}^{N} i^{-\gamma} \frac{1}{2}\left[s^{2}-(s-c(i))^{2}\right] d i+\int_{N}^{\infty} i^{-\gamma} \frac{1}{2}\left[s^{2}-s^{2}\right] d i$. To prevent divergence of the first integral we must have $\gamma<1$. By the normalization of $v($.$) the second integral is zero and does not$ diverge. We can then restrict our attention to the utility function $u(\{c\})=\int_{0}^{N} i^{-\gamma} \frac{1}{2}\left[s^{2}-(s-c(i))^{2}\right] d i$.

${ }^{8}$ While this particular structure is an assumption at this stage, we will see below that it will be the equilibrium outcome of the model. Over time new goods are continuously introduced and the chronological sequence of innovations follows the hierarchy of wants. When innovators are protected by patent with finite duration, the 'new 'goods are protected and charged the monopoly price, whereas the patents for 'old' goods have expired and supplied on competitive markets.
} 
$[p(i)-1]\left[\max \left(0, s-i^{\gamma} p(i) \lambda\right)\right]$. The solution is given by

$$
p(i)=\max \left[1, \frac{s+i^{\gamma} \lambda}{2 i^{\gamma} \lambda}\right] \text { for } i \in(a N, N] .
$$

\subsection{Equilibrium composition of demand and the structure of prices}

We can now characterize the composition of demand and the structure of prices in the static equilibrium, given the representative agent's budget $E$ and the measure of available goods $N$. This will be done separately for the two scenarios that can occur in equilibrium. In the first case, the consumer cannot afford all supplied goods because the non-negativity constraints for low-priority goods become binding. In the second case, the consumer is rich enough to purchase all goods that are supplied on the market. We discuss these two cases in turn. (The conditions under which the two respective regimes occur are studied in Section 5 below.)

When the consumer does not purchase all available goods, the measure of consumed products falls short of the measure of available goods $N$. If good $i$ is consumed in positive amounts and supplied at the monopoly price, we know from (2) and (3) that the consumed quantity equals $c(i)=\frac{1}{2}\left(s-i^{\gamma} \lambda\right)$. The equilibrium demand is decreasing in $i$ which means that the optimal quantity of low-priority goods is smaller. It also means that there is a good, call it $n$, such that for goods $i>n$ the optimal level of demand is zero whereas all goods $i<n$ are consumed in positive amounts. It turns out convenient to express the endogenous variables $c(i)$ and $p(i)$ in terms of the endogenous variable $n$ rather than $\lambda$. From $c(n)=\frac{1}{2}\left(s-n^{\gamma} \lambda\right)=0$ it is straightforward to calculate $\lambda=\frac{s}{n^{\gamma}}$. Substituting this into equations (2) and (3) we get the equilibrium composition of demand, and the equilibrium structure of prices

$$
c(i)= \begin{cases}s\left[1-\left(\frac{i}{n}\right)^{\gamma}\right], & i \in[0, a N] \\ \frac{s}{2}\left[1-\left(\frac{i}{n}\right)^{\gamma}\right], & i \in(a N, n] \\ 0, & i \in(n, N]\end{cases}
$$

and

$$
p(i)= \begin{cases}1, & i \in[0, a N] \\ \frac{1}{2}\left[1+\left(\frac{n}{i}\right)^{\gamma}\right], & i \in(a N, n] \\ 1, & i \in(n, N] .\end{cases}
$$

According to equations (4) and (5), what matters for prices and quantities is the relative position in the hierarchy of needs, $i / n$. We also see that the 'steeper' the hierarchy (the higher 
is $\gamma$ ) the more important is the relative position. The above expressions for $p(i)$ and $c(i)$ are determined for a given measure of consumed goods $n$. However, $n$ itself is an endogenous variable. To get the optimal value of $n$ we substitute equations (4) and (5) into the budget constraint to get

$$
E=\int_{0}^{n} p(i) c(i) d i=s n\left[\frac{a N}{n}-\frac{1}{4}\left(\frac{3\left(\frac{a N}{n}\right)^{1+\gamma}+1}{1+\gamma}-\frac{1-\left(\frac{a N}{n}\right)^{1-\gamma}}{1-\gamma}\right)\right] .
$$

This equation implicitly defines the number of consumed goods $n$ as a function of expenditures $E$, available goods $N$, and other parameters of the model. ${ }^{9}$ In particular, we note that $E$ and $N$ are exogenous from the point of view of the consumer. Moreover, we see from the above equation that $n$ is homogenous of degree one in $E$ and $N$ : when $E$ and $N$ increase by some factor, the equilibrium value of $n$ increases by the same factor.

Now consider the alternative scenario that the consumer chooses to consume all available goods in positive amounts. Obviously, this is the case if $c(N)=\frac{1}{2}\left(s-N^{\gamma} \lambda\right)>0$. Also here it is convenient to replace $\lambda$. However, we cannot express $\lambda$ in terms of the optimal bundle of consumed goods $n$ which is trivially determined by the number of available goods $N$. Instead we express $\lambda$ in terms of the price of the good that has least priority in consumption, that is by the endogenous variable $p(N) \equiv p$. From (3) it is straightforward to express the marginal utility of income as $\lambda=\frac{s}{N^{\gamma}(2 p-1)}$. The same expression (3) can be used to express the monopoly prices for the goods $i \in(a N, N]$ in terms of $p$ as $p(i)=\frac{1}{2}\left[1+\left(\frac{N}{i}\right)^{\gamma}(2 p-1)\right]$. The structure of prices and the equilibrium composition of demand can now be expressed as

$$
c(i)= \begin{cases}s\left[1-\left(\frac{i}{N}\right)^{\gamma} \frac{1}{2 p-1}\right] & i \in[0, a N] \\ \frac{s}{2}\left[1-\left(\frac{i}{N}\right)^{\gamma} \frac{1}{2 p-1}\right], & i \in(a N, N]\end{cases}
$$

and

$$
p(i)= \begin{cases}1, & i \in[0, a N] \\ \frac{1}{2}\left[1+\left(\frac{N}{i}\right)^{\gamma}(2 p-1)\right], & i \in(a N, N] .\end{cases}
$$

\footnotetext{
${ }^{9}$ It is straightforward to verify that the right-hand-side of $(6)$ is monotonically increasing in $n$. When no intersection occurs for $n \leq N$, the equilibrium is characterized by $n=N$. In that case equation (6') below is relevant. Note that when, respectively, $n=N$ and $p=1$, the right-hand-sides of the equations (6) and (6') become identical.
} 
Note that, in equilibrium, a higher $p$ means higher prices for all goods and this goes hand in hand with higher equilibrium consumption for all goods. The reason for this apparently strange result is that the equilibrium depends crucially on the consumer's budget $E$ relative to the measure of supplied goods $N$. If $E$ is large relative to $N$, there is high demand for each good which means that monopolists can charge high prices.

The variables $c(i)$ and $p(i)$ are determined by the endogenous variable $p$, the profitmaximizing price chosen by the monopolist who supplies the good $N$. Just like before, the equilibrium depends on the consumer's budget $E$, the measure of available goods $N$, and other parameters of the model. To see the relationship between $p, E$, and $N$, we insert equations $\left(4^{\prime}\right)$ and (5') into the consumer's budget constraint

$$
E=\int_{0}^{N} p(i) c(i) d i=s N\left[a-\frac{1}{4}\left(\frac{3 a^{1+\gamma}+1}{(1+\gamma)(2 p-1)}-(2 p-1) \frac{1-a^{1-\gamma}}{1-\gamma}\right)\right]
$$

This expression implicitly defines $p$ as a function of $E, N$, and other parameters of the model. We observe that $p$ is homogenous of degree zero in $E$ and $N$ : when $E$ and $N$ grow pari passu, $p$ remains unchanged.

\section{The Dynamics of the Economy}

\subsection{Technical Progress and the Resource Base}

To keep things simple we develop our arguments assuming that labor is the only production factor. (In Section 6 below we discuss the more general case when not only labor but also physical capital is used in production.) Production requires a fixed ('innovation' or 'research') input of $\tilde{F}(t)$ units of labor, and a variable labor input of $\tilde{b}(t)$ per unit of output ( $t$ denotes a continuous time index). Denoting by $w(t)$ the wage rate, we have innovation costs $w(t) \tilde{F}(t)$ and marginal costs of production $w(t) \tilde{b}(t)$. We assume $\tilde{b}(t)=\frac{b}{A(t)}$ and $\tilde{F}(t)=\frac{F}{A(t)}$, where $A(t)$ is the aggregate knowledge stock, and $F, b>0$ are exogenous parameters. These assumptions imply that productivity growth, an increase in $A(t)$, is uniform across sectors and also across activities. Assuming uniform productivity growth across products makes sure that all heterogeneity comes from the demand side which is the focus of our analysis. Assuming uniform productivity growth across (production and research) activities is important for the existence of a constant growth path. Along this path wages grow with productivity so that 
marginal production costs $w(t) b(t)$ and innovation costs $w(t) \tilde{F}(t)$ are constant over time. In what follows we take marginal cost as the numeraire, hence $w(t) \tilde{b}(t)=1$ for all $t$.

In accordance with much of the endogenous growth literature we assume that the aggregate knowledge stock is proxied by the amount of previous innovations activities. These consist of the measure of goods that are actually available on the market, so we have $A(t)=N(t)$ and $\tilde{b}(t)=\frac{b}{N(t)}$ and $\tilde{F}(t)=\frac{F}{N(t)} \cdot{ }^{10}$

The labor force is normalized to 1 and, in equilibrium, there is full employment. At date $t$, $\dot{N}(t)$ new goods are introduced and the necessary employment level to perform the innovation input is $\dot{N}(t) \frac{F}{N(t)}$. The necessary employment level to produce the demanded consumers goods is $\frac{b}{N(t)} \int_{0}^{n(t)} c(i, t) d i$. Thus with full employment of the labor resources we have

$$
1=\frac{\dot{N}(t)}{N(t)} F+\frac{b}{N(t)} \int_{0}^{n(t)} c(i, t) d i
$$

\subsection{The Innovation Process}

Innovations occur because firms are granted patents and earn profits as long as their market is protected from competitors. The value of an innovation that occurs at date $t, \Pi(t)$, equals the present value of the profit flow that accrues to the innovating firm. This flow starts at the date when consumers begin to purchase this product and ends when patents have expired. We denote the flow profit at date $\tau$ of the date- $t$ innovator (the firm which produces good $N(t)$ ) by $\pi(N(t), \tau)=[p(N(t), \tau)-1] c(N(t), \tau)$.

When consumers purchase all available varieties $n=N$ the date- $t$ innovator earns positive profits right from the start, that is throughout the interval $[t, t+\Delta]$ where the exogenous policy parameter $\Delta$ denotes the duration of the patent. When consumers cannot afford all available varieties $n<N$, the innovator has initially no demand. Consumers purchase only

\footnotetext{
${ }^{10}$ Note that our assumption on knowledge spillovers differs from the standard 'love-for-variety' model (Grossman and Helpman, 1992). In that model productivity grows only in research but not in production. In the hierarchical model instead there has to be technical progress otherwise innovations comes to a halt because consumers are not willing to reduce consumption on high-priority goods if new goods come along. Hence without technical progress in production, sooner or later the whole labor force will be employed to satisfy the demand of consumers on the already existing goods. Our assumption could be justified, e.g., using the argument of Young (1993a): If the invention of a new good $i$ leads as a by-product to the discovery of a new intermediate input and if the final goods are produced by combining these inputs using a constant returns to scale CES technology, the productivity of the output sector rises linearly in the number of these inputs.
} 
the goods with high priority, that is all goods in the interval $[0, n(t))$ and no goods in the interval $[n(t), N(t)]$. In that case, innovators have a waiting time until consumers are willing to purchase their product. Denoting this waiting time by $\delta$, the profit flow $\pi(N(t), \tau)$ is zero at dates $\tau \in[t, t+\delta]$, positive at all dates $\tau \in(t+\delta, t+\Delta]$, and zero for $\tau>t+\Delta$. To see how $\delta$ is determined note that, when consumers start to buy good $N(t)$ at date $t+\delta, N(t)$ is the good with least priority in the consumption bundle. Hence $\delta$ is given by $n(t+\delta)=N(t)$. In the dynamic equilibrium $n(t)$ grows at the constant rate $g$ and we have $n(t+\delta)=n(t) e^{\delta g}=N(t)$.

Innovation costs are constant over time and given by $w F$. Assuming free access to the research sector, there is entry as long as innovation costs fall short of the value of an innovation. Hence in equilibrium, when all profit opportunities are exploited, we must have $w F \geq \Pi(t)$, with strict equality whenever innovations take place. Defining $R(\tau, t)=\int_{t}^{\tau} r(s) d s$ as the cumulative interest rate, the zero-profit condition can be stated as

$$
w F=\int_{t+\delta}^{t+\Delta}[p(N(t), \tau)-1] c(N(t), \tau) e^{-R(\tau, t)} d \tau
$$

\subsection{Optimal Savings}

We now consider the optimal intertemporal allocation of consumption expenditures of the representative consumer. Assuming that an agent maximizes utility over an infinite horizon, the objective function is given by

$$
U(t)=\int_{t}^{\infty} \frac{u(\tau)^{1-\sigma}}{1-\sigma} e^{-\rho(\tau-t)} d \tau
$$

where $u(\tau) \equiv \int_{0}^{\infty} i^{-\gamma} \frac{1}{2}\left[s^{2}-(s-c(i, \tau))^{2}\right] d i$ is the aggregator for within-period consumption levels. The parameter $\sigma$ measures the willingness to shift the composite $u(\tau)$ across time and $\rho$ is the subjective rate of time preference. The above objective function is maximized subject to the intertemporal budget constraint

$$
\int_{t}^{\infty} E(\tau) e^{-R(\tau, t)} d \tau \leq \int_{t}^{\infty} w(\tau) e^{-R(\tau, t)} d \tau+V(t)
$$

where $E(\tau) \equiv \int_{0}^{N(\tau)} p(i, \tau) c(i, \tau) d i$ denotes the level of consumption expenditures at date $\tau$ and $V(t)$ denotes the assets that the consumer owns at the initial date $t$. Setting up the Lagrangian and taking derivatives with respect to $c(i, \tau)$ yields the first order condition

$$
u(\tau)^{-\sigma} i^{-\gamma}(s-c(i, \tau)) e^{-\rho(\tau-t)}=\mu e^{-R(\tau, t)} p(i, \tau)
$$


where $\mu$ is the Lagrangian multiplier. This first order condition (and the intertemporal budget constraint) determine the optimal consumption levels for each good at each date - given the consumer's lifetime income and the prices of the various goods at all dates. The above first order condition must hold for all $i$ and $\tau$, so it must also hold for $i=n(\tau)$. Hence we can set $i=n(\tau)$ in the above first order condition, then take logs and the derivative with respect to time $\tau$. This yields

$$
-\sigma \frac{\dot{u}(\tau)}{u(\tau)}-\gamma \frac{\dot{n}(\tau)}{n(\tau)}-\frac{\partial c(n(\tau), \tau)}{\partial \tau} \frac{1}{s-c(n(\tau), \tau)}-\rho=-r(\tau)+\frac{\partial p(n(\tau), \tau)}{\partial \tau} \frac{1}{p(n(\tau), \tau)} .
$$

Our analysis focuses on steady state growth paths. For describing the evolution of consumption expenditures along this path, the following Lemma is helpful.

Lemma 1 In the static equilibrium the maximized instantaneous utility at date $\tau, \hat{u}(\tau)$, can be written as $\hat{u}(\tau)=\frac{E(\tau)^{1-\gamma}}{1-\gamma} K\left(\frac{n(\tau)}{N(\tau)}, p(n(\tau), \tau), a(\tau) ; s, \gamma\right)$.

Proof see Appendix.

A balanced growth path has the following features. (i) $n(\tau), N(\tau)$ and $E(\tau)$ grow at the same rate (so that output and consumption grow at the same rate and a constant fraction, if any, of patented goods is not produced and consumed). (ii) $a(\tau)$ is constant over time (so that a constant fraction of sectors supplies their products on competitive markets). ${ }^{11}$ (iii) The price of good $x N(\tau), p(x N(\tau), \tau)$, does not change over time ( $x \leq 1$ is a positive constant). This means that, at all dates, the same price is attached to a given relative hierarchical position $x=i / N .^{12}$ Similarly, $c(x N(\tau), \tau)$ the consumption level of the good at relative position $x$ is also the same at all dates $\tau$.

Using these balanced growth properties and Lemma 1 the above first order condition simplifies considerably. Lemma 1 and properties (i) - (iii) imply that, along the balanced growth

\footnotetext{
${ }^{11}$ To see the relationship between $a, g$, and $\Delta$, note that, at date $t+\Delta$ all patents granted at $t$ and before are expired, and all patents granted after $t$ are not yet expired. With $N(t)$ markets at date $t$, there are $N(t+\Delta)=e^{g \Delta} N(t)$ markets at date $t+\Delta$. Hence, at date $t+\Delta$, the measure of competitive markets equals $N(t)$. Obviously, a fraction $a=e^{-g \Delta}$ is competitive and a fraction $1-a=1-e^{-g \Delta}$ is monopolistic.

${ }^{12}$ Note that each good $i$ starts out with hierarchical position $x=1$ (as $i=N(\tau)$ at the innovation date $\tau$ ) and gradually approaches relative position $x=0$ (when $N$ becomes very large relative to $i$ ). As a result, the price of a particular good is initally rising (when the product is monopolistically supplied) and then falls to marginal costs (when patents have expired the market becomes competitive). From analogous arguments, the profil of consumption levels can be inferred.
} 
path, we must have $\dot{u} / u=-\gamma \dot{E} / E$. Property (iii) holds for any positive constant $x \leq 1$, hence they are also true for $x=n(\tau) / N(\tau)$ so we have $\partial p(n(\tau), \tau) / \partial \tau=\partial c(n(\tau), \tau) / \partial \tau=0$ at all dates. This allows us to rewrite the above first order condition as

$$
\frac{\dot{E}(t)}{E(t)}=g=\frac{r(t)-\rho}{\sigma(1-\gamma)+\gamma}
$$

Clearly, when $E(t)$ grows at a constant rate, the interest rate $r(t)$ is also constant. In the symmetric case $(\gamma=0)$ we get the familiar equation $g=(r-\rho) / \sigma \cdot{ }^{13}$

\section{Long-Run Growth Equilibrium}

We now describe the general equilibrium of the model. We start by defining the equilibrium growth path. Then we establish the conditions under which a unique path exists. A discussion of the consistency of this equilibrium with the Kaldor facts of economic growth and of the patterns of structural change along this path is devoted to the next Section.

\subsection{Definition of Equilibrium Growth Path}

The equilibrium growth path is characterized by the following conditions: (i) consumers allocate lifetime expenditures optimally across time and goods, (ii) firms set prices that maximize profits, (iii) research firms leave no profit opportunities unexploited, (iv) the labor force is fully employed and (v) aggregate consumption and investment expenditures and the value of aggregate production grow at the same rate.

When consumers do not purchase all available goods, $n<N$, conditions (i) and (ii) are satisfied when, for each date $t$, equations (9), (4) and (5) hold. ${ }^{14}$ Equation (9) implies that

\footnotetext{
${ }^{13}$ It is interesting to note that the effect of $\gamma$ on the growth rate of consumption is ambiguous (recall that $\gamma<1$ ). A higher $\gamma$ raises $g$ when $\sigma>1$ and it decreases $g$ if $\sigma<1$. The intuition is subtle: With $\gamma>0$, the expenditures $E(t)$ enter themselves as a concave function in the utility function. The growth rate of consumption depends on how fast marginal utility falls. In the symmetric case marginal utility declines at rate $\sigma$. The asymmetry has two effects. On the one hand, the intertemporal substitution effect causes marginal utility to fall only at the rate $\sigma(1-\gamma)$; on the other side the intratemporal substitution implies that marginal utility falls at rate $\gamma$. In total, marginal utility falls at rate $\sigma(1-\gamma)+\gamma$ which is less than $\sigma$ if $\sigma>1$ and bigger than $\sigma$ if $\sigma<1$.

${ }^{14}$ The time index $t$ enters equations (4) and (5) because $n$ depends on $t$.
} 
consumer allocate expenditure optimally across time. If equations (4) and (5) are satisfied consumers allocate expenditures optimally across goods, given profit maximizing prices of firms; and firms set profit-maximizing prices given the optimal quantities of consumers. Condition (iii) is satisfied when the zero-profit equation (8) holds, and condition (iv) is satisfied when the resource constraint (7) holds. Condition (v) is satisfied because our specification of preferences boils down to a (maximized) felicity function that is CRRA in total consumption expenditures.

The model has a convenient recursive structure and we can reduce the above system of equations to two equations in two unknowns: the economy-wide growth rate $g$ and the innovator's waiting time $\delta$. To obtain the first equation substitute equation (4) into the resource constraint (7) and use the definition $g=\frac{\dot{N}(t)}{N(t)}$. Moreover we make use of the fact that in the dynamic equilibrium we have $n(t)=e^{-\delta g} N(t)$ and $a N(t)=N(t) e^{-\Delta g}$. The former relation says that the relation between consumed and available goods is constant and given by $e^{-\delta g}$. The latter relation says that the fraction of competitive markets among all markets is constant and given by $e^{-\Delta g}$. Thus the resource constraint (7) can be rewritten as

$$
1=g F+\frac{b s}{2} e^{-g \delta}\left[e^{-g(\Delta-\delta)}-\frac{e^{-g(1+\gamma)(\Delta-\delta)}+1}{1+\gamma}+1\right] .
$$

The second equation in $g$ and $\delta$ is obtained by substituting equations (9), (4) and (5) into the zero profit condition (8). Here we note that from (4) $c(N(t), \tau)=\frac{s}{2}\left[1-\left(\frac{N(t)}{N(\tau)}\right)^{\gamma}\right]=$ $\frac{s}{2}\left[1-e^{-g \gamma(\tau-t)}\right]$ and from (5) $p(N(t), \tau)=\frac{1}{2}\left[1+\left(\frac{N(\tau)}{N(t)}\right)^{\gamma}\right]=\frac{1}{2}\left[1+e^{g \gamma(\tau-t)}\right]$. This yields

$$
w F=\frac{s}{4}\left(\frac{1-e^{-\phi(\Delta-\delta)}}{\phi}-2 \frac{1-e^{-(\phi+g \gamma)(\Delta-\delta)}}{\phi+g \gamma}+\frac{1-e^{-(\phi+2 g \gamma)(\Delta-\delta)}}{\phi+2 g \gamma}\right) \cdot e^{-\delta(\phi+g \gamma)}
$$

where we used the definition $\phi=r-g \gamma$ and that, from (9), $r=\rho+g(\sigma(1-\gamma)+\gamma)$.

Similarly, when consumers purchase all available goods, $n=N$, conditions (i) and (ii) are satisfied when equations (9), (4') and (5') hold; and conditions (iii) and (iv) are also given by equations (7) and (8). This system of equations can be conveniently reduced to two equation with two unknowns: the growth rate $g$ and the innovator's entry price $p$. The solution procedure is analogous to before except that now (4') and (5') are relevant. This yields

$$
1=g F+\frac{b s}{2}\left[e^{-g \Delta}-\frac{e^{-g \Delta(1+\gamma)}+1}{(1+\gamma)(2 p-1)}+1\right]
$$

for the resource constraint, and

$$
w F=\frac{s}{4}\left(\frac{1-e^{-\phi \Delta}}{\phi}(2 p-1)-2 \frac{1-e^{-(\phi+g \gamma) \Delta}}{\phi+g \gamma}+\frac{1-e^{-(\phi+2 g \gamma) \Delta}}{\phi+2 g \gamma} \frac{1}{2 p-1}\right)
$$


for the zero-profit condition.

\subsection{A Unique Equilibrium}

To examine existence and uniqueness of the dynamic equilibrium we analyze the respective equilibrium conditions graphically. We denote the resource constraint by $R$ and the zero profit condition by $\Pi$ and draw $R$ and $\Pi$ in a $(\delta, g, p)$-diagram. This allows us to discuss the above two scenarios simultaneously (Figure 1). In both parts of Figure 1 the vertical axis measures the growth rate $g$. In the left part of Figure 1 the horizontal axis measures the innovator's waiting time $\delta$ (from right to left, starting at $\delta=0$ ), and in the right part of Figure 1 the horizontal axis measures the innovators' entry price $p$ (starting at $p=1$ ). Observe that $\delta=0$ and $p=1$ is the limiting case where the innovator has neither a waiting time nor enough demand to charge a price above marginal cost.

We now discuss the shape of the two curves in turn. To avoid confusion we denote the resource constraint in $(g, \delta)$-space by $\tilde{R}$ and the one in $(g, p)$-space by $R$. Similarly, we have $\Pi$ and $\tilde{\Pi}$ for the zero-profit condition. The $R$-curve in $(g, \delta)$ space is defined by the equation $1=\tilde{R}(g, \delta)$ and $\tilde{R}(g, \delta)$ is given by the right-hand-side of equation (10). The $\Pi$-curve is defined by the equation $w F=\tilde{\Pi}(g, \delta)$ where $\tilde{\Pi}(g, \delta)$ is given by the right-hand-side of equation (11). Similarly, the $R$ - and the $\Pi$-curve in $(g, p)$ space are defined by $1=R(g, p)$ and $w F=\Pi(g, p)$ where $R(g, p)$ and $\Pi(g, p)$ by given by the right-hand-side of equations (10') and (11').

\section{Figure 1}

The shape of the $\Pi$-curve Consider first the $(g, \delta)$ space. When the consumer does not buy all available goods, $n<N$, innovators have a waiting time $\delta>0$ until they can sell their product. The slope of the $\tilde{\Pi}$-curve is given by $d g / d \delta=-\tilde{\Pi}_{\delta} / \tilde{\Pi}_{g}$. A higher $\delta$ decreases profits so $\tilde{\Pi}_{\delta}<0$ (where $\tilde{\Pi}_{x}$ denotes the partial derivative of $\tilde{\Pi}$ with respect to $x$ ). This simply results from discounting: the longer one has to wait for a given profit flow, the lower is the present value of this flow. This effect is enhanced by the fact that, due to a fixed patent duration $\Delta$, the period during which the innovator earns positive profits does not only start later but also becomes shorter (recall that we measure $\delta$ from left to right).

The impact of the growth rate $g$ on the value of an innovation $\Pi$, i.e. the sign of $\tilde{\Pi}_{g}$ is ambiguous. In a world with homothetic preferences where all goods enter the utility function 
in a symmetric way, a higher growth rate always lowers the value of an innovation. This is because in equilibrium, a higher growth rate is always associated with a higher interest rate that discounts future revenues more strongly (see the discussion in Romer, 1990). With hierarchic preferences instead, we have a second effect: a higher growth rate raises demand for the most recent innovator's product and leads to faster growth of the innovator's market. This leads to higher future prices and higher future profits which raises the value of an innovation. The size of the latter effect depends crucially on the value of $\gamma$, the steepness of the hierarchy: Lemma 2 below shows that the first effect always dominates if $\gamma$ is low. Instead, if the hierarchy parameter $\gamma$ is large, the demand effect of higher growth dominates the interest rate effect at low level of $g$ (see Figure 1). It is important to note that a steep hierarchy is a necessary condition for the regime $n<N$ to be possible at all. When innovators have no initial demand, there are innovation incentives only if, after the waiting period $\delta$, demand grows very quickly.

When consumers purchase all available products, $n=N$, innovators have no waiting time $\delta=0$ and charge an entry price larger than marginal cost $p \geq 1$. The slope of the $\Pi$-curve is given by $d g / d p=-\Pi_{p} / \Pi_{g}$. How does the value of an innovation depend on $p$ ? We know from $\left(5^{\prime}\right)$ that a higher entry price $p$ for the most recent innovator's product means higher prices for all other goods in equilibrium. Moreover, from equation (4') a higher $p$ is also associated with larger equilibrium consumption of each variety. Hence each monopolist has larger profits, so we have $\Pi_{p}>0$.

The impact of the growth rate $g$ on the value of an innovation is just like before. The demand effect increases, whereas the interest effect decreases the value of an innovation. The demand effect can dominate at low growth rates when the hierarchy is steep enough, whereas the interest effect dominates at high growth rates.

Lemma 2 a. The zero profit condition crosses the p-axis at $p_{Z}=1+\left(\left(1+\frac{b s}{F} \frac{1-e^{-\Delta \rho}}{\rho}\right)^{\frac{1}{2}}-1\right)^{-1}$

b. The value of an innovation falls monotonically in the growth rate if $\gamma \leq \frac{\sigma\left(p_{Z}-1\right)}{1+\sigma\left(p_{Z}-1\right)}$ (flat hierarchy). In this case, the zero profit constraint is a monotonically increasing curve in the $(g, p)$-space.

c. For g sufficiently high, $\Pi_{g}<0$ and $\tilde{\Pi}_{g}<0$.

Proof see Appendix. 
The shape of the $R$-curve The slope of the resource constraint $R$ can be derived in an analogous way as before by calculating, respectively, $d g / d \delta=-\tilde{R}_{\delta} / \tilde{R}_{g}$ and $d g / d p=-R_{p} / R_{g}$ for the two regimes. A higher waiting time $\delta$ reduces labor demand. The reason is that a higher $\delta$ decreases the demand for each product. (To see this use $n=e^{-\delta g} N$ in equation (4)). This means that $\tilde{R}_{\delta}<0$. Similarly, a higher entry price $p$ is associated with higher consumption levels for all goods (see equation (4')), and thus with a larger demand for labor in the whole economy. For this reason $R_{p}>0$.

A higher growth rate $g$ has an ambiguous effect on the demand for labor resources. On the one hand, there is the direct effect from a larger demand for workers in the research sector. On the other hand, there is an indirect effect which is due to the increase in the size of the monopolistic sector. (Recall from Section 4 above that, with a given patent duration $\Delta$, a fraction $e^{-g \Delta}$ of all goods is supplied by competitive producers and a fraction $1-e^{-g \Delta}$ by monopolistic firms). The larger the monopolistic sector, the higher the overall price level, and the lower consumption demand. Hence an increase in $g$ leads to a lower demand for production workers. The following Lemma shows that the latter effect may dominate at low $g$, whereas the former effect always dominates at high $g$. We therefore have $R_{g}>0$ if $g$ is high and vice versa. We summarize this discussion in the following

Lemma 3 a. The resource constraint crosses the p-axis at $p_{R}=\frac{1}{2}\left[1+\frac{1}{1+\gamma} \frac{b s}{b s-1}\right]$ if $1<b s \leq$ $\frac{1+\gamma}{\gamma}$.

b. If $b s \leq 1$, the resource constraint is monotonically falling in the $(g, p)$ - and $(\delta, g)$-space and reaches asymptotically the growth rate $\hat{g}$ implicitly defined by $1=\hat{g} F+\frac{b s}{2}\left(1+e^{-\hat{g} \Delta}\right)$.

c. If $b s>\frac{1+\gamma}{\gamma}$, even at $g=0$ not all products can be produced, the share of products consumed $x=\frac{n}{N}$ is then given by the equation $1=\frac{b s}{2}\left[1-x^{-\gamma} \frac{1}{1+\gamma}+x \frac{\gamma}{1+\gamma}\right]$.

d. For $g$ sufficiently high, $R_{g}>0$ and $\tilde{R}_{g}>0$.

Proof see Appendix.

Remark If $b s \leq 1$, the $R$-curve never hits the p-axis. All consumers could consume all varieties at the saturation level and there are still resources available for research.

Having discussed the shape of the two curves we can consider the general equilibrium of the model. In this equilibrium both the resource constraint and the zero profit condition have to be satisfied which is the case at the point of intersection $E$ in Figure $1 .{ }^{15}$ A sufficient condition

\footnotetext{
${ }^{15}$ Figure 1 suggests that the equilibrium exists if the $\Pi$-curve hits the $p$-axis to the left of $R$-curve. For most
} 
for uniqueness is $\gamma \leq \frac{\sigma\left(p_{Z}-1\right)}{1+\sigma\left(p_{Z}-1\right)}$ (flat hierarchy) and $b s \leq 1$, since then the two equilibrium curves are monotonically increasing or falling, respectively.

Proposition 1 a. If the exogenous parameters satisfy $p_{Z}<p_{R}$ or if $b s \leq 1$, there exists a general equilibrium with a positive growth rate.

b. A sufficient condition for a unique general equilibrium is $b s \leq 1$ and $\gamma \leq \frac{\sigma\left(p_{Z}-1\right)}{1+\sigma\left(p_{Z}-1\right)}$.

Proof Part b. see Appendix.

\section{Structural Change and the Kaldor Facts}

In this Section we discuss of how the famous stylized facts mentioned by Kaldor (1961) can be reconciled with a continuous change in the structure of production and employment. We proceed in four steps. First, as the Kaldor facts of economic growth are partly concerned with physical capital, we have to show that the equilibrium established in the last Section - when enriched with physical capital - meets Kaldor's criteria. Second, we describe the patterns of structural change that occur along the long-run growth path, in particular the rise and fall of the employment shares in the various sectors that occurs during the process of economic development. Then, we study the critical role of the two taste parameters that characterize the hierarchy of needs, the saturation level $s$ and the steepness of the hierarchy $\gamma$. Finally, we perform a simple quantitative exercise where we confront our model with data on structural change in several industrialized countries.

\subsection{The Kaldor Facts}

In a celebrated paper, Kaldor (1961) mentions that a reasonable growth model should capture the following criteria: (i) a constant growth rate of output and labor productivity; (ii) a constant increase in capital per worker; (iii) a constant long-term interest rate; (iv) a constant capital-output ratio; (v) a constant share of profits in output; and (vi) differences in growth rate of labor productivity across countries.

The long-run growth equilibrium established above assumes that labor is the only production factor. In order to discuss Kaldor's stylized facts in a meaningful way, we have to parameter values, simulations show that the equilibrium is unique. 
bring physical capital into the picture. Assume that each consumer good is produced with the same constant-returns-to-scale technology $F[k(i, t), A(t) l(i, t)]$ and that also capital goods are produced with that technology. $k(i, t)$ and $l(i, t)$ denote, respectively, the amounts of physical capital and labor employed in sector $i$ at date $t .{ }^{16} A(t)$ is the stock of (labor-augmenting) technical knowledge and it is again assumed that $A(t)=N(t)$. Given the linear homogeneity of the production function we can write $f(\kappa(i, t))=F\left[\frac{k(i, t)}{A(t) l(i, t)}, 1\right]$ with $\kappa(i, t)$ as the capital-labor ratio in efficiency units of labor and $f(\kappa(i, t))$ as the production function in intensive form.

When financial markets are perfect, savings yield the same returns, irrespective of whether they are invested in physical capital or in research. With a competitive market for capital goods, the rental price of capital equals $r(t)+\delta$, where $\delta$ is the rate of depreciation of physical capital. The rental price is the same in each sector. Each firm has to pay a wage rate $w$ and a rental price of physical capital $r+\delta$. Cost minimization implies that each firm chooses the same capital-labor ratio. This implies that marginal production costs are the same in all sectors. In a steady state, where the interest rate is constant, the capital labor ratio is constant over time. For firms that operate under competitive conditions we must have $f^{\prime}(\kappa(i, t))=r$. Because all firms choose the same capital labor ration we have, for all $i$ and $t, \kappa(i, t)=\kappa$. When $\kappa$ is constant, the wage rate per efficiency unit of labor is also constant. Obviously, the wage rate per worker grows at the same rate as productivity.

The final step is to show that the capital output ratio is constant. To see this, suppose that employment in investment sector is constant. First, since $\kappa$ is constant, output of investment goods $I$ grows at the same rate as productivity. Physical capital evolves according to $\dot{K}=$ $I-\delta K$, thus the capital stock grows also at the same rate as productivity. Second, output in the research sector is given by $w(t) g F$ which also grows at the same rate as productivity. Third, the value of output in the consumption sector also grows at the same rate. This is because, with marginal costs constant over time, the price setting behavior is the same as before. Hence the profit share in the consumption goods sector is constant and the Euler equation (9) still holds. In the steady state, the optimal growth rate of consumption expenditures equals the growth rate of productivity. Hence when wages grow at this rate, employment in the consumption goods sector is constant. This confirms our initial guess that employment in the investment

\footnotetext{
${ }^{16}$ Since technology is linear homogenous, the distribution of capital on the several firms in sector $i$ plays no role.
} 
sector is constant. Output equals $Y(t)=E(t)+I(t)+w(t) g F$ and therefore grows at the same rate as productivity. Hence the capital-output ratio is constant. We summarize this discussion in the following Proposition.

Proposition 2 Along the steady growth path the Kaldor facts of economic growth are satisfied.

\section{$5.2 \quad$ Structural Change}

The equilibrium growth path exhibits continuous structural change: At a given date, many different goods exist and each good has a different income elasticity. Declining sectors with a low income elasticity and a falling share of production and employment co-exist with expanding sectors that have a high income elasticity and expanding share of production and employment. Hence there is uneven development and continuous reallocation of labor across sectors of production. In this Section we describe the pattern of structural change in more detail. We will concentrate on the regime $n<N$ and briefly discuss the regime $n=N$ at the end of the section.

To make the changes in the structure of consumption and employment explicit consider the life cycle of product $i$. How does demand and employment of an innovator increase over time? To answer this question take equation (4) and note that along the long-run growth path we have $n(t)=e^{-\delta g} N(t)$. Given the initial value of $N$, the growth rate $g$, and the innovator's waiting time $\delta$, we know the equilibrium value of $n(t)$. From equation (4) the consumption level $c(i, t)$ and the corresponding level of employment $l(i, t)=b \frac{c(i, t)}{N(t)}$ can be calculated.

Figure 2 shows the Engel-curves for good $i=N(t)$. We draw $c(i, t)$ against total output in the production sector $E(t)$. As $E(t), N(t)$, and $n(t)$ grow at the same rate the shape of the Engel-curve can be derived from (4). Demand is initially zero and the non-negativity constraints are still binding. This means at low income levels consumers cannot afford the product. Once a critical income level has been reached consumers start to buy. Increases in income initially lead to a strong expansion of the market, followed by decreasing growth rates and finally stagnating demand in the long term once consumption approaches the saturation level $s$. We note further that Engel-curves show a discontinuity at the point of time when patents expire. At this date the market opens up for competition, the price falls to marginal 
cost, and the demand level jumps up.

\section{Figure 2}

The following proposition summarizes the patterns of structural change by referring to the income elasticities of demand and employment. The 'gross' income elasticities take account of both the direct income effect on demand and of the indirect effects due to changes in the own price and the prices of all other (monopolistically supplied) products as incomes grow.

Proposition 3 a) Along the steady growth path, each new good starts out as a luxury with high income elasticity and ends up as a necessity with low income elasticity. The 'gross' income elasticity of demand for good $i$ is $\gamma \frac{s-c(i, t)}{c(i, t)}$. b) Industries producing luxuries (with gross income elasticity larger than unity) expand their employment whereas industries producing necessities (with gross income elasticity lower than unity) loose employment. The 'gross' income elasticity for employment is $\gamma \frac{s-c(i, t)}{c(i, t)}-1$.

This proposition holds for both regimes. As $E(t), N(t)$ and $n(t)$ grow at the same rate, we can calculate the income elasticity as $\frac{d c(i, t)}{d n(t)} \frac{n(t)}{c(i, t)}$ or $\frac{d c(i, t)}{d N(t)} \frac{N(t)}{c(i, t)}$. For both regimes, the expressions in the proposition can be derived, respectively, from equations (4) and (4'). Part b) of the proposition obtains because the employment required to produce $c(i, t)$ is $l(i, t)=b \frac{c(i, t)}{N(t)}$, hence $\frac{d l(i, t)}{d N(t)} \frac{N(t)}{l(i, t)}=\frac{d c(i, t)}{d N(t)} \frac{N(t)}{c(i, t)}-1$.

Part a) of the proposition shows that, for a given product, the demand elasticity is initially high and decreases towards zero as consumption approaches the saturation level $s{ }^{17}$ In other words, despite constant growth rates of macroeconomic aggregates, goods with high and low income elasticities coexist and continuous structural change takes place. This means our model captures the Engel-Kindleberger idea of consumption cycles. Whether or not a good is a luxury or a necessity, depends on the level of development. Income elasticities change as the economy gets richer, and a good that has been a luxury good in the initial period of the product cycle becomes a necessity after incomes have sufficiently grown.

Part b) of the proposition discusses the evolution of the employment share in a particular product line. Whether or not employment increases or decreases, depends on whether demand

\footnotetext{
${ }^{17}$ Also with respect to demand elasticities note the discontinuity at the date when patents expire. At this date the demand level jumps up and thus there is a sudden decrease in the income elasticity.
} 
grows faster or slower than productivity. In other words, the industry-specific employment level reflects the outcome of a race between the growth of demand and productivity as the economy gets richer. Initially the growth of demand is larger than the aggregate growth rate and employment increases over time. However, after incomes have sufficiently grown, the growth of market demand lags behind the aggregate growth rate and the industry labor share decreases.

\section{Other Equilibria}

If the parameter values satisfy $p_{Z} \geq p_{R}$ a stagnation equilibrium or multiple equilibria may arise (see Lemmas 2 and 3 for the definitions of $p_{Z}$ and $p_{R}$ ). In that case, the $\Pi$-curve cuts the $p$-axis to the right of the $R$-curve.

Stagnation In a stagnation equilibrium the value of an innovation is (equal or) smaller than the costs of an innovation, which implies that no research will be undertaken. Not surprisingly, this outcome is likely if research costs $F$ are high. Also in the stagnatory state, the full employment condition has to be satisfied, hence the equilibrium point lies on the $R$ curve and is located where the $R$-curve intersects the horizontal axis (at $g=0$ ). If $n=N$, the $R$-curve hits the horizontal axis in the right part of Figure 1 . This occurs at $p_{R}>1$. When this inequality is violated the regime $n=N$ is not feasible and we are in the regime $n<N$. As the economy does not grow, the waiting time $\delta$ is not a meaningful endogenous variable because $\delta$ will necessarily be infinite. As stated in Lemma $3 \mathrm{c}$, the resource constraint has to be solved for $x=n / N$, the share of available products that is actually consumed. In such an equilibrium there are firms that know how to produce the goods $i \in(n, N]$, but no production ever takes place since demand given the (constant) income level is too small.

Multiple equilibria If $p_{Z} \geq p_{R}$ and if the two curves cross the model exhibits multiple equilibria. We then have three equilibria: the stagnation point and the two points of intersection of the $\Pi$ - and the $R$-curve.

\section{Figure 3}

Multiple equilibria can arise because the $\Pi$-curve is not necessarily monotonic. When the hierarchy is steep enough (high $\gamma$ ) the П-curve is backward bending at low levels of $g$, see 
Lemma $2 \mathrm{~b}$. The intercept of the resource constraint with the horizontal axis, $p_{R}$, shifts to the left with an increase in $\gamma$. According to Proposition 1, this implies that multiple equilibria become more likely.

The reason for multiplicity is a demand externality: when preferences have a hierarchic structure the demand of a previous innovator depends on the economy-wide growth rate. If innovators expect high growth they expect that the demand for their products expands more quickly implying that future prices, quantities, and profits are larger. So higher economywide growth stimulates the incentive to innovate. If innovators expect low growth, profit expectations and the resulting incentives to innovate are correspondingly low. Hence low growth rates are sustained by pessimistic expectations and vice versa. Obviously, this demand externality is at work independently of the particular length of a patent; in particular it holds even when protection is forever. ${ }^{18}$ We summarize this discussion in the following

Proposition 4 A sufficiently steep hierarchy ( $\gamma$ sufficiently large) may lead to multiple equilibria. In such equilibria expectations are self-fulfilling: optimistic expectations are sustained with high innovative activities, pessimistic expectations are sustained by low (or no) innovative activities.

We prove proposition 4 by an example. Assume the following parameter values: $F=8$, $L=1, \Delta=\infty, b s=10 / 3, \sigma=2, \rho=0.02, \gamma=0.95$ (note that the hierarchy parameter $\gamma$ is very close to unity). In that case, there are three equilibria: $\left(p_{1}, g_{1}\right)=(1.135,0),\left(p_{2}, g_{2}\right)=$ $(1.080,0.79 \%)$, and $\left(\delta_{3}, g_{3}\right)=(8.79,7.03 \%)$. Hence, two equilibria exhibit a positive growth rate and one is stagnatory. Further, for these parameter values, the high growth equilibrium features a waiting time $\delta_{3}=8.79$ years for the innovators.

\section{$7 \quad$ A Simple Quantitative Illustration}

While the main purpose of our model is theoretical, it may nevertheless be interesting to look at its quantitative implications. In this section we provide such a simple quantitative exercise. Maddison (1987) documents the huge reallocation of labor in six major industrialized countries

\footnotetext{
${ }^{18}$ As shown by Laussel and Nyssen (1999) who multiple equilibria may also arise due to a finite patent length. However in the present model the possibility of multiplicity does not hinge on the length of patents. Provided that $\gamma$ is sufficiently large, mulitple equilibria may occur even if patent length is infiinte.
} 
(France, Germany, Japan, Netherlands, U.K. and U.S.). Table 1 shows that the average U.S. employment share in agriculture was as high as $46 \%$ in 1870 and has decreased to $5.5 \%$ by 1984. During the same period the average employment share in the service sector has increased from $26.4 \%$ to $62.2 \%$.

\section{Table 1}

Although, the common three sector division is questionable as the structural composition has changed dramatically also within these sectors we may think of a loose association with the sectoral trichotomy in our model: Products satisfying the most urgent needs (mostly, but not entirely, agricultural products) are ranked first and products satisfying least urgent wants (to a large extent, but not entirely, service products) are ranked highest. To make the quantitative exercise as simple as possible, we assume that goods $i$ between 0 and 1 are agricultural products, goods between 1 and $x$ are manufacturing products, and goods with higher index are exclusively services. The labor used to set-up a new firms (R\&D labor) is counted as services. ${ }^{19}$

Can our model explain the observed patterns of structural change documented in Table 1? As starting point we choose $N(0)$ such that the labor share in agriculture amounts to $50 \%$, manufacturing to $30 \%$, and services to $20 \%$. The exogenous parameters are set to $F=8$, $L=1, \Delta=\infty, b s=10 / 3, \sigma=2, \rho=0.02, \gamma=0.77$ and $x=4$. This yields an equilibrium growth rate of $g=2.2 \%$ and a price level for the most luxurious good of $p=1.06$.

\section{Figure 4}

The simulations are presented in Figure 4. We see that the model is able to reproduce the observed patterns of structural change remarkably well. Agriculture exhibits a steady decline from 50 percent to about 5 percent after 120 years. Services stay constant at early stages (as long as $N(t)<x=4)$ but exhibit a steady increase thereafter and reach a level of roughly 80 percent after 120 years. Our model also generates a hump shape in the manufacturing labor

\footnotetext{
${ }^{19}$ By this assumption we capture the empirical fact that, even in a less developed society, a large fraction of the population works in the service sector, such as retail trade, housing services, etc. A precise way to capture a positive service labor share in the model would be treating services as an input in production of final output. In the present context we assume that services enter as an input only via set-up costs: This should be viewed as a shortcut necessary to capture the empirical facts.
} 
share. Starting with 30 percent, the manufacturing labor share reaches 47 percent around 35 years and decreases thereafter reaching roughly 15 percent after 120 years.

Contrasting this simulation with the country average in Table 1 (last column) reveals that the model predicts the huge movement of labor out of agriculture remarkably well. The model also predicts a hump shape in the evolution of the manufacturing share that is observed in all countries displayed in Figure 4 (with the exception of Japan). We also see that (i) the increase in the manufacturing labor share is initially too strong; (ii) the peak is reached too early; and (iii) the decrease in manufacturing employment is too strong. It should be clear, however, that this result is due to the extreme assumption on the mapping of the consumption hierarchy into the sectoral trichotomy. Assume, more realistically, that "intermediate" needs are covered mostly by manufacturing products but to some extent also by services; and that the most luxurious wants are covered mostly by services but to some extent also by manufacturing products. $^{20}$ Then the transition to a service economy would be smoother. In early stages of economic development, workers leaving the agricultural sector would not only enter the manufacturing sector but also the service sector. In later stages, workers leaving old manufacturing industries would not only enter the service sector but also new manufacturing industries. In sum, relaxing the above extreme mapping assumption, would lead to (i) a smaller increase in the manufacturing labor share, (ii) a delay in the date when the manufacturing labor share peaks, and (iii) a smaller decrease in the manufacturing labor share thereafter. Hence we conclude our model is capable of fitting the empirical patterns of structural change quite well. Needless to say, while our model can capture important features of the process of structural change it does not fit these patterns perfectly. A full story has to account for technological heterogeneity across sectors.

\section{Discussion}

Our analysis has made a number of strong assumptions. We have based our analysis on the concept of hierarchic preferences and have specified these preferences in a particular way. Moreover we have abstracted from technological asymmetries across sectors and have assumed

\footnotetext{
${ }^{20}$ More precisely, assume that with probability $\theta(i)$ a new product is a manufacturing good and with probability $1-\theta(i)$ a new product is a service, with $\theta^{\prime}(i) \leq 0$. Our simulation makes the extreme assumption that $\theta(i)=1$ for $i \in(1,4]$ and $\theta(i)=0$ for $i>4$.
} 
that all sectors participate equally from technical progress. In this section we discuss the robustness of our results with respect to deviations from these assumptions.

Assumptions on preferences To generate a balanced growth path we have assumed (i) a felicity function that is additively separable across the various products, (ii) a quadratic subutility function, and (iii) a consumption hierarchy that weights the products with a power function. The assumption of additive separability is primarily made for tractability. ${ }^{21}$

The functional form of the subutility function $v(c)$ is not essential. As shown by Foellmi (2003) any form of $v(\cdot)$ that satisfies the usual assumptions $v^{\prime}(c)>0$ and $v^{\prime \prime}(c)<0$ would do. We only need a small set of regularity conditions: To guarantee that the utility integral is well defined we have to normalize $v(0)=0$; and to allow for an equilibrium with binding non-negativity constraints we must have $v^{\prime}(0)<\infty$ (which also implies that utility is nonhomothetic). The quadratic form of $v(\cdot)$ has been chosen to obtain closed-form solutions. Moreover, its saturation point captures a basic idea of any model of hierarchic consumption in a very stylized way: Consumers move to goods with less priority, once they have saturated their basic needs. ${ }^{22}$

The restriction of the weighting function to take the power form $i^{-\gamma}$ is essential. It implies that demand functions (and monopoly prices) only depend on the relative (rather than the absolute) position of the product in the hierarchy. As a result, the maximized static utility function can be expressed as a function of total (current) expenditure levels, the function taking the constant elasticity form with parameter $\gamma$. In other words, in intertemporal problems with a continuum of goods, assuming additive separability and weighting by a power function is the equivalent of assuming a CRRA-felicity function in the one-good growth model. ${ }^{23}$ In either case, these functional forms guarantee a constant rate of consumption growth when rates of

\footnotetext{
${ }^{21}$ The assumption of separability implies that "Pigou's law", proportionality of income and price elasticities, holds in our model. Clements and Selvanathan (1994), in an empirical study based on aggregate cross-country consumption data, find empirical evidence in favor of Pigou's law.

${ }^{22}$ For instance, it is not necessary to have a utility function with a saturation level. In an earlier version of this paper (Foellmi and Zweimüller, 2003) we have used the felicity function $v(c)=\ln (c+q)$ with $q$ as a positive constant. This yields qualitatively similar results (and explicit solutions) except that the demand elastity for a given product remains strictly positive.

${ }^{23}$ More precisely, Foellmi (2003) has shown that a felicity function of the form $u(\{c(i)\})=\int_{0}^{\infty} i^{-\gamma} v(c(i)) d i-$ is CRRA in expenditure levels if the price of good $i$ can be expressed as a function of its relative position $i / N$ only. This clearly holds true in the present model.
} 
interest and time preference are constant over time.

Sectoral differences in productivity levels and productivity growth The second important assumption relied on identical supply conditions across sectors. We have motivated this assumption by various arguments - including lack of a strong empirical case for sectoral differences in productivity growth rates. Nevertheless, it can be shown that sectoral differences in productivity levels and/or scopes for productivity growth can be integrated in our model.

The case is straightforward when only productivity levels (but not rates of technical progress) differ across sectors. Consider the simplest case, when labor is the only production factor, and the labor coefficient in product line $i$ is given by $a(i)=a+\varepsilon(i)$ with $\varepsilon(i)$ being the deviation of sector $i$ from average productivity. Assume that the distribution of $\varepsilon$ has the properties $E \varepsilon(i)=0, E \varepsilon(i)^{2}=\sigma^{2}$, and $E \varepsilon(i) \varepsilon(i+\Delta)=0$ for $\Delta \neq i$. The latter assumption implies that there are no systematic differences in productivity level between high- and low-priority goods. Absent such differences, there is no mechanism that would lead to violation of the Kaldor facts. Note however, that patterns of structural change may be affected. Allowing for random differences in technology across sectors may reverse the order in which new goods and services are introduced. When $a(i) \gg a(j)$ so that productivity in sector $i$ is much lower than in $j$, then good $j$ may be introduced earlier even if $i$ has higher priority, so that $i<j$. To compensate for the higher costs, the innovator has to charge higher prices. To generate the same profit flow, high-cost products have to be introduced later (when monopoly prices are higher or the waiting time is shorter), whereas low-cost earlier than in the basic case of equal costs. Obviously, very similar arguments can be made when there are two factors of production, and when production functions differ "randomly" across product lines.

The situation becomes slightly more tricky when there are sectoral differences in technical progress. Assume, there is uncertainty with respect to technical progress at the date when a new product is introduced. Each good starts out with the "state-of-the-art" technology. With probability $\beta$ a new sector is "dynamic" (costs fall with the number of previous innovations $N(t)$, just like before) and "stagnant" with probability $1-\beta$ (no change in costs of production). This implies that, at each date, there co-exist dynamic sectors with "state-of-the-art" productivity levels $b / N(t)$ and stagnant sectors with $b / N(s)$ where $s$ denotes the period when the product is introduced. (The latter assumption says that all new sectors start out with state- 
of-the-art productivity but only dynamic sectors experience productivity growth). Assume that $\beta$ is uncorrelated with the priority of a product, so sectoral differences are "random" in the sense that low- and high-priority goods have the same scope for technical progress. Products that experience technical progress will experience unchanged marginal costs and rising prices. Products that experience no technical progress will suffer from the "cost disease". Unlike in the Baumol model, stagnant products will disappear from the market because sooner or later costs will become larger than the prohibitive price. The steady-state growth path is characterized by a constant fraction of output and employment in stagnant sectors, though the composition of these sectors changes over time as new goods enter and old goods disappear. Hence, our framework can capture, by way of a natural extension, also the fact that goods and services disappear over time.

A further dimension of technological heterogeneity across sectors involves the scope for technological spillovers. Suppose there are differences across sectors in the contribution of innovation $i$ to the aggregate stock of knowledge. With a probability $\alpha$, the by-product of a new innovation is additional knowledge that makes factors more productive in all other sectors, and with probability $1-\alpha$, there are no such knowledge spillovers. As a result, the aggregate stock of knowledge is given by $A(t)=\alpha N(t)$. In other words, productivity levels are only $\alpha$ times as high as in the basic model, the equilibrium outcome of our model remains otherwise unchanged.

A final point concerns differences in technologies between investment and consumption goods. The analysis above has shown that the consumption sector can be aggregated nicely, the model could be extended to a two sector framework à la Rebelo (1991). It is well known that a balanced growth path exists within that model even though consumption and investment goods are produced with different technologies and experience different rates of productivity growth. Such a framework would account for the empirical evidence in Greenwood et al. (1997).

The above discussion has highlighted conditions on technological asymmetries that are compatible with the Kaldor facts. We have seen that the absence of a correlation between the relevant technology parameters and the hierarchy index $i$ is essential. It is straightforward to see how the long-run growth path is affected when these conditions are violated. If there are systematic correlations over extended intervals along the consumption hierarchy growth 
rates will no longer be constant. Hence our framework can generate growth cycles, periods of productivity slowdowns and productivity revivals.

\section{Conclusions and Extensions}

We have presented a model that reconciles two dominant features of the long-run growth process: the dramatic changes in the structure of production and employment; and the Kaldor facts of economic growth. Our model has focused on the demand-explanation of structural change which is based on the idea that households expand their consumption along a hierarchy of needs. In such a context structural change results from differences in income elasticities across sectors. We have proposed a specification of hierarchic preferences featuring realistic patterns of structural change while at the same time generating an equilibrium growth path consistent with the Kaldor facts.

Our analysis has focused on an endogenous growth framework. Studying hierarchic preferences in an $R \& D$ driven endogenous growth model highlight interesting interactions between structural change and long-run growth. On the one hand, the aggregate growth rate depends on structural change because innovation incentives are crucially determined by the growth rates in the new industries. On the other hand, the speed of structural change is itself determined by aggregate growth. The resulting complementarities between sectoral and aggregate growth open up the possibility for multiple equilibria. Hence our model is not only capable of yielding insights into the process of growth and structural change, but sheds also light on the question why some countries experience high long-term growth and many industries take off, while in other countries we see neither a change in the production structure nor increases in aggregate productivity.

Finally, we have also shown by means of a simple quantitative illustration, that our model is able to capture realistic patterns of structural change. In particular, our simulation show that the model is capable of reproducing the great structural transformation from agriculture towards industry and services. We also show that the model predicts, consistent with observed patterns of change, that the manufacturing employment first increases and then decreases in the course of economic development.

Our model can be extended in several directions. We think that two extensions are most promising. First, while our analysis has focused on a representative consumer, the introduction 
of consumer heterogeneity is potentially interesting. As preferences are non-homothetic, rich and poor households will consume different consumption bundles which opens up a new channel by which income inequality could affect growth and structural change (Foellmi and Zweimüller, 2005). Second, hierarchic preferences in a world economy with rich and poor countries would imply interesting patterns of growth and the international division of labor. Our model provides a natural way of modelling the Linder-hypothesis (Linder, 1961) and/or the product-cycle hypothesis (Vernon, 1966). A rich country faces high home-demand and hence will innovate early. The poor country will first import new goods, but later on start to imitate. Hence rich countries will produce new goods with a high income elasticity and poor countries will produce old goods with a low elasticity. Our set-up may also be useful to understand the mixed empirical evidence concerning the Prebisch/Singer-hypothesis (Prebisch, 1950, Singer, 1950) according to which the terms of trade for the poor countries deteriorate as their exports are concentrated on goods with low income elasticities. (For a static model along these lines, see Matsuyama, 2000). 


\section{References}

Acemoglu, Daron and Veronica Guerrieri (2005); Capital Deepening and Non-Balanced Economic Growth, mimeo, MIT.

Baumol, William J. (1967); Macroeconomics of Unbalanced Growth: The Anatomy of the Urban Crisis, The American Economic Review 57: 415-426.

Caselli, Francesco and Wilbur John Coleman II (2001); The U.S. Structural Transformation and Regional Convergence: A Reinterpretation, Journal of Political Economy 109: 584-616.

Chari, V.V. and Hugo Hopenhayn (1991); Vintage Human Capital, Growth, and the Diffusion of New Technology, Journal of Political Economy 99: 1142-1165.

Clements, Kenneth W. and Saroja Selvanathan (1994); Understanding Consumption Patterns, Empirical Economics 10: 69-110.

Echevarria, Cristina (1997); Changes in Sectoral Composition Associated with Economic Growth, International Economic Review 38: 431-452.

Engel, Ernst (1857); Die Productions- und Consumptionsverhältnisse des Königreichs Sachsen, Zeitschrift des Statistischen Büreaus des Königlich Sächsischen Ministeriums des Inneren, No. 8 und 9 .

Foellmi, Reto (2003); Consumption Structure and Macroeconomics, Doctoral Dissertation, University of Zurich.

Foellmi, Reto and Josef Zweimüller (2003); Structural Change and Balanced Growth with a Hierarchy of Needs, mimeo, University of Zurich.

Foellmi, Reto and Josef Zweimüller (2005); Income Distribution and Demand-Induced Innovations, CEPR Working Paper No. 4985.

Gollin, Douglas, Stephen Parente, and Richard Rogerson (2002); The Role of Agriculture in Development, American Economic Review, Papers and Proceedings 92: 160-164.

Gollin, Douglas, Stephen Parente, and Richard Rogerson (2004); The Food Problem and the Evolution of International Income Levels, Yale Economic Growth Center Discussion Paper No. 899.

Greenwood, Jeremy, Zvi Hercowitz, and Per Krusell (1997); Long-Run Implications of Investment-Specific Structural Change, American Economic Review 87: 342-362.

Greenwood, Jeremy and Gokce Uysal (2005); New Goods and the Transition to a New Economy, Journal of Economic Growth, 10, 99-134. 
Grossman, Gene M. and Elhanan Helpman (1992); Innovation and Growth in the Global Economy, MIT Press, Cambridge MA.

Hansen, Gary D. and Edward C. Prescott (2002); Malthus to Solow, American Economic Review 92: 1205-17.

Houthakker, Hendrick S. (1987); Engel Curve, in: J.Eatwell, M. Milgate, and P. Newman (eds.), The New Palgrave Dictionary of Economics, London, Macmillan, pp. 142-143.

Jones Charles I. (1999); Growth with or without Scale Effects, American Economic Review, Papers and Proceedings 89: 139-144.

Kaldor, Nicholas (1961); Capital Accumulation and Economic Growth, in: F. Lutz and D.C. Hague (eds.), The Theory of Capital, New York: St. Martin's Press, pp.177-222.

Katona, George (1964); The Mass Consumption Society, New York: McGraw-Hill.

Kindleberger, Charles (1989); Economic Laws and Economic History, Cambridge, Cambridge University Press.

Kongsamut, Piyabha, Sergio Rebelo, and Danyang Xie (2001); Beyond Balanced Growth, Review of Economic Studies 68: 869-882.

Laitner, John (2000); Structural Change and Economic Growth, Review of Economic Studies 67: 545-561.

Laussel, Didier and Jules Nyssen (1999); Endogenous Growth and Multiplicity due to Finite Patents' Lifetime, Economics Letters 63: 167-173.

Linder, Staffan B. (1961); An Essay on Trade and Transformation, Stockholm, Almqvist \& Wicksell.

Maddison, Angus (1987); Growth and Slowdown in Advanced Capitalist Economies: Techniques of Quantitative Assessment, Journal of Economic Literature 25: 649-698.

Matsuyama, Kiminori (1992); Agricultural Productivity, Comparative Advantage, and Economic Growth, Journal of Economic Theory 58: 317-334.

Matsuyama, Kiminori (2000); A Ricardian Model with a Continuum of Goods under Nonhomothetic Preferences: Demand Complementarities, Income Distribution, and North-South Trade, Journal of Political Economy 108: 1093-1120.

Matsuyama, Kiminori (2002); The Rise of Mass Consumption Societies, Journal of Political Economy 110: 1035-1070.

Matsuyama, Kiminori (2005), Structural Change, forthcoming in: New Palgrave Dictionary 
of Economics, London, Macmillan.

Ngai, Rachel and Christopher Pissarides (2005); Structural Change in a Multi-Sector Model of Growth, mimeo, LSE.

Parente, Stephen L. and Edward C. Prescott (2004); A Unified Theory of the Evolution of International Income Differences, Federal Reserve Bank of Minneapolis Research Department Staff Report 333.

Pasinetti, Luigi (1981); Structural Change and Economic Growth, CUP, Cambridge MA, London.

Prebisch, Raul (1950); The Economic Development of Latin America and Its Principal Problems, New York: UN.

Rebelo, Sergio (1991); Long-Run Policy Analysis and Long-Run Growth, Journal of Political Economy 99: 500-521.

Romer, Paul (1990); Endogenous Technological Change, Journal of Political Economy 98: S71-S102.

Singer, Hans W. (1950); The Distribution of Gains Between Borrowing and Investing Countries, American Economic Review 40: 473-485.

Thompson, Peter (2001); The Microeconomics of an R\&D-Based Model of Endogenous Growth, Journal of Economic Growth 6: 263-283.

Vernon, Raymond S. (1966); International Investment and International Trade in the Product Cycle, Quarterly Journal of Economics 80: 190-207.

Young, Alwin (1993a); Substitution and Complementarity in Endogenous Innovation, Quarterly Journal of Economics 108: 775-807.

Young, Alwin (1993b); Invention and Bounded Learning by Doing, Journal of Political Economy 101: 443-472.

Zweimüller, Josef (2000); Schumpeterian Entrepreneurs Meet Engel's Law: The Impact of Inequality on Innovation-Driven Growth, Journal of Economic Growth 5: 185-206. 


\section{Appendix}

Proof of Lemma 1 Consider first the regime $n<N$. To get the maximized utility $\hat{u}$ for a given level of expenditures $E$ and a given menu of goods $N$, we insert equilibrium quantities (4) into the utility function (1) After some manipulations this yields (we omit time indices in what follows)

$$
\hat{u}=\frac{n^{1-\gamma}}{1-\gamma} \frac{s^{2}}{8}\left(3+\left(a \frac{N}{n}\right)^{1-\gamma}+2(1-\gamma) \frac{a N-n}{n}-(1-\gamma) \frac{1+3\left(a \frac{N}{n}\right)^{1+\gamma}}{(1+\gamma)}\right)
$$

which we can write as $\hat{u}=\frac{n^{1-\gamma}}{1-\gamma} \psi\left(\frac{n}{N}, a ; \gamma, s\right)$. We know from (6), that we can write $E=\operatorname{sn} \phi\left(\frac{n}{N}, a ; \gamma, s\right)$ which implies $n=\frac{E}{s \phi\left(\frac{n}{N}, a ; \gamma, s\right)}$. Inserting this latter expression into the above utility function yields

$$
\hat{u}=\frac{E^{1-\gamma}}{1-\gamma} K\left(\frac{n}{N}, p=1, a ; s, \gamma\right)
$$

where $K\left(\frac{n}{N}, p=1, a ; s, \gamma\right)=\frac{\psi\left(\frac{n}{N}, a ; \gamma, s\right)}{\left[s \phi\left(\frac{n}{N}, a ; \gamma, s\right)\right]^{1-\gamma}}$.

We proceed in a similar way for regime $n=N$. This yields for maximized utility

$$
\hat{u}=\frac{N^{1-\gamma}}{1-\gamma} \frac{s^{2}}{8}\left(3+a^{1-\gamma}+\frac{2(1-\gamma)(a-1)}{2 p-1}-\frac{(1-\gamma)\left(1+3 a^{1+\gamma}\right)}{(1+\gamma)(2 p-1)^{2}}\right)
$$

which can be written as $\hat{u}=\frac{N^{1-\gamma}}{1-\gamma} \Psi(p, a ; \gamma, s)$. We know from equation (6') that we can write $E=$ $s N \Phi(p, a ; \gamma, s)$. Solving for $N$ and substituting into the above utility expression yields

$$
\hat{u}=\frac{E^{1-\gamma}}{1-\gamma} K\left(\frac{n}{N}=1, p, a ; s, \gamma\right)
$$

where $K\left(\frac{n}{N}=1, p, a ; s, \gamma\right)=\frac{\Psi(p, a ; \gamma, s)}{[s \Phi(p, a ; \gamma, s)]^{1-\gamma}}$. 
Proof of Lemma 2 We know from the zero-profit condition (11') that

$$
\begin{aligned}
\Pi_{g} & \equiv \frac{\partial \Pi(t)}{\partial g}=\int_{t}^{t+\Delta} \frac{s}{4}\left[\begin{array}{c}
-\sigma(1-\gamma)(\tau-t) e^{-[\rho+g \sigma(1-\gamma)](\tau-t)}(2 p-1) \\
-(\sigma(1-\gamma)+2 \gamma)(\tau-t) e^{-[\rho+g \sigma(1-\gamma)+2 g \gamma](\tau-t)} \frac{1}{2 p-1} \\
+2(\sigma(1-\gamma)+\gamma)(\tau-t) e^{-[\rho+g \sigma(1-\gamma)+g \gamma](\tau-t)}
\end{array}\right] d \tau \\
& =\int_{t}^{t+\Delta} \frac{s}{4}\left[\begin{array}{c}
-\sigma(1-\gamma)(2 p-1) \\
-(\sigma(1-\gamma)+2 \gamma) e^{-2 g \gamma(\tau-t)} \frac{1}{2 p-1} \\
+2(\sigma(1-\gamma)+\gamma) e^{-g \gamma(\tau-t)}
\end{array}\right](\tau-t) e^{-[\rho+g \sigma(1-\gamma)](\tau-t)} d \tau \\
& =: \int_{t}^{t+\Delta} \frac{s}{4} \Theta(p, g)(\tau-t) e^{-[\rho+g \sigma(1-\gamma)](\tau-t)} d \tau
\end{aligned}
$$

We will show the following: If $\left.\frac{\partial \Pi(t)}{\partial g}\right|_{g=0} \leq 0$ then $\frac{\partial \Pi(t)}{\partial g}<0$ for all $g>0$. Hence, $\left.\frac{\partial \Pi(t)}{\partial g}\right|_{g=0} \leq 0$ is sufficient for $\Pi$ to have always a positive slope. $\left.\frac{\partial \Pi(t)}{\partial g}\right|_{g=0}$ can be calculated as

$$
\begin{gathered}
\frac{s}{4}\left[-\sigma(1-\gamma)(2 p-1)-(\sigma(1-\gamma)+2 \gamma) \frac{1}{2 p-1}+2(\sigma(1-\gamma)+\gamma)\right] \int_{t}^{t+\Delta}(\tau-t) e^{-\rho(\tau-t)} d \tau \leq 0 \\
\Longleftrightarrow \Theta(p, 0)=-\sigma(1-\gamma)(2 p-1)-(\sigma(1-\gamma)+2 \gamma) \frac{1}{2 p-1}+2(\sigma(1-\gamma)+\gamma) \leq 0 \\
\Longleftrightarrow \gamma \leq \frac{\sigma(p-1)}{1+\sigma(p-1)} \Longleftrightarrow p \geq \frac{\sigma(1-\gamma)+\gamma}{\sigma(1-\gamma)} \Longleftrightarrow 2 p-1 \geq \frac{\sigma(1-\gamma)+2 \gamma}{\sigma(1-\gamma)} .
\end{gathered}
$$

Note that $p$ depends on $g$. If $\left.\frac{\partial \Pi(t)}{\partial g}\right|_{g=0} \leq 0$, the zero profit constraint has a positive slope, i.e. we must have $p^{\prime}(g) \geq 0$. Together with the lower bounds of $p$ above we can determine the sign of the partial derivatives of $\Theta(p, g)$

$$
\begin{aligned}
\Theta_{p} & =-2 \sigma(1-\gamma)+\frac{2}{(2 p-1)^{2}}(\sigma(1-\gamma)+2 \gamma) e^{-2 g \gamma(\tau-t)} \\
& \leq-2 \sigma(1-\gamma)+\frac{2 \sigma^{2}(1-\gamma)^{2}}{(\sigma(1-\gamma)+2 \gamma)^{2}} e^{-2 g \gamma(\tau-t)}<0 \\
\Theta_{g} & =-2(\sigma(1-\gamma)+\gamma) \gamma(\tau-t) e^{-g \gamma(\tau-t)}+2(\sigma(1-\gamma)+2 \gamma) \gamma(\tau-t) e^{-2 g \gamma(\tau-t)} \frac{1}{2 p-1} \\
& \leq-2(\sigma(1-\gamma)+\gamma) \gamma(\tau-t) e^{-g \gamma(\tau-t)}+2 \sigma(1-\gamma) \gamma(\tau-t) e^{-2 g \gamma(\tau-t)}<0
\end{aligned}
$$

Hence $\Theta(p(g), g)<\Theta(p(0), g)<\Theta(p(0), 0) \leq 0$ which completes the proof. 
b. Insert $g=0$ into the zero profit condition (11') (since demand does not grow when $g=0$, an equilibrium with positive waiting time $\delta$ is impossible)

$$
\begin{aligned}
\frac{F}{b} & =\frac{s}{4} \frac{1-e^{-\rho \Delta}}{\rho}\left(2 p_{z}-1+\frac{1}{2 p_{z}-1}-2\right) \\
4 \frac{F}{b s} \frac{\rho}{1-e^{-\rho \Delta}} & =\left(\sqrt{2 p_{z}-1}-\frac{1}{\sqrt{2 p_{z}-1}}\right)^{2} \\
2 \sqrt{\frac{F}{b s} \frac{\rho}{1-e^{-\rho \Delta}}} & =\sqrt{2 p_{z}-1}-\frac{1}{\sqrt{2 p_{z}-1}}
\end{aligned}
$$

Note that only the positive root is relevant since $2 p_{z}-1>1$. We denote $\sqrt{2 p_{z}-1}=x$, the equation above can then be written as $x^{2}-2 \sqrt{\frac{F}{b s} \frac{\rho}{1-e^{-\rho \Delta}}} x-1=0$. This quadratic equation has the solution $x=\sqrt{2 p_{z}-1}=\sqrt{\frac{F}{b s} \frac{\rho}{1-e^{-\rho \Delta}}}+\sqrt{\frac{F}{b s} \frac{\rho}{1-e^{-\rho \Delta}}+1}$. Solving for $p_{z}$ yields the claim of the Lemma.

c.

$$
\lim _{g->\infty} \Pi_{g}=\int_{t}^{t+\Delta} \frac{s}{4} \Theta(p, g)(\tau-t) e^{-[\rho+g \sigma(1-\gamma)](\tau-t)} d \tau<0
$$

and

$$
\lim _{g->\infty} \tilde{\Pi}_{g}=e^{-\delta r} \int_{t}^{t+\Delta-\delta} \frac{s}{4} \Theta(1, g)(\tau-t) e^{-r(\tau-t)} d \tau-\delta \sigma(1-\gamma) \Pi(t)<0
$$

since

$$
\lim _{g->\infty} \Theta(p, g)=-\sigma(1-\gamma)(2 p-1)<0
$$


Proof of Lemma 3 a. Inserting $g=0$ into the resource constraint (10') yields

$$
1=b s\left[1-\frac{1}{(1+\gamma)(2 p-1)}\right]=: f(p)
$$

$1 \leq p<\infty$ implies $b s \frac{\gamma}{1+\gamma} \leq f(p)<b s$. Hence, the equation can only be fulfilled if $1<b s \leq \frac{1+\gamma}{\gamma}$. Solving the equation yields $p_{R}=\frac{1}{2}\left[1+\frac{1}{1+\gamma} \frac{b s}{b s-1}\right]$.

b. If $p$ goes to infinity in equation (10'), the condition follows directly.

c. Replace $\delta$ by the new variable $x=\frac{n}{N}=e^{-\delta g}$. Equation (10) now reads:

$$
1=g F+\frac{b s}{2}\left[1-\frac{e^{-g(1+\gamma) \Delta}}{1+\gamma} x^{-\gamma}+\frac{\gamma}{1+\gamma} x\right]
$$

Inserting $g=0$ yields the condition in the Lemma.

d. The derivatives with respect to $g$ are, respectively, $R_{g}=F-\frac{b s}{2} \Delta\left[e^{-g \Delta}-\frac{1}{2 p-1} e^{-g \Delta(1+\gamma)}\right]$ and $\tilde{R}_{g}=F-\frac{b s}{2}(\Delta-\delta) e^{-g \delta}\left[e^{-g(\Delta-\delta)}-e^{-g(\Delta-\delta)(1+\gamma)}\right]-\delta \frac{b s}{2} e^{-g \delta}\left[e^{-g(\Delta-\delta)}-\frac{e^{-g(1+\gamma)(\Delta-\delta)}+1}{1+\gamma}+1\right]$. Hence, $\lim _{g->\infty} R_{g}=\lim _{g->\infty} \tilde{R}_{g}=F>0$. 
Proof of Proposition 1 With flat hierarchy, we showed that the П-curve is monotonically increasing, and so an equilibrium is only possible with $p>1$. It remains to show that the $R$-curve monotonically decreasing if $b s \leq 1$, which would guarantee uniqueness. Lemma $2 \mathrm{~b}$. says that $R$ approaches $\hat{g}$, defined by $1=\hat{g} F+\frac{b s}{2}\left(1+e^{-\hat{g} \Delta}\right)$. The right hand side of the latter expression is a convex function in $g$ and must therefore have a positive slope at $g=\hat{g}$. Thus, $F-\frac{b s}{2} \Delta e^{-\hat{g} \Delta}>0$. But this implies $R_{g}=F-\frac{b s}{2} \Delta e^{-g \Delta}+\frac{b s}{2} \Delta \frac{1}{2 p-1} e^{-g \Delta(1+\gamma)}>\frac{b s}{2} \Delta \frac{1}{2 p-1} e^{-g \Delta(1+\gamma)}>0$. 


\begin{tabular}{|c|c|c|c|c|c|c|c|c|}
\hline \multicolumn{9}{|c|}{$\begin{array}{c}\text { Table 1 } \\
\text { StRUCTURAL CHANGE 1870-1984 } \\
\text { (sectoral employment as a fraction of total employment) }\end{array}$} \\
\hline \multirow{5}{*}{ Agriculture } & & France & Germany & Japan & Netherlands & U.K. & U.S. & Average \\
\hline & 1870 & 49.2 & 49.5 & 67.5 & 37.0 & 22.7 & 50.0 & 46.0 \\
\hline & 1913 & 37.4 & 34.6 & 64.3 & 26.5 & 11.0 & 32.3 & 34.4 \\
\hline & 1950 & 28.5 & 22.2 & 48.3 & 13.9 & 5.1 & 13.0 & 21.8 \\
\hline & 1984 & 7.6 & 5.5 & 8.9 & 4.9 & 2.6 & 3.3 & 5.5 \\
\hline \multirow[t]{4}{*}{ Industry } & 1870 & 27.8 & 28.7 & 13.8 & 29.0 & 42.3 & 24.4 & 27.7 \\
\hline & 1913 & 33.8 & 37.8 & 13.9 & 33.8 & 44.8 & 29.3 & 32.2 \\
\hline & 1950 & 34.8 & 43.0 & 22.6 & 40.2 & 46.5 & 33.3 & 36.7 \\
\hline & 1984 & 32.0 & 40.5 & 34.8 & 26.4 & 32.4 & 28.0 & 32.4 \\
\hline \multirow[t]{4}{*}{ Services } & 1870 & 23.0 & 21.8 & 18.7 & 34.0 & 35.0 & 25.6 & 26.4 \\
\hline & 1913 & 28.8 & 27.6 & 21.8 & 39.7 & 44.2 & 38.4 & 33.4 \\
\hline & 1950 & 36.7 & 34.8 & 29.1 & 45.9 & 48.4 & 53.7 & 41.4 \\
\hline & 1984 & 60.4 & 54.0 & 56.3 & 68.7 & 65.0 & 68.7 & 62.2 \\
\hline
\end{tabular}

Source: Maddison (1984) 
Figure 1: The equilibrium values of the growth rate $g$ and waiting time $\delta$

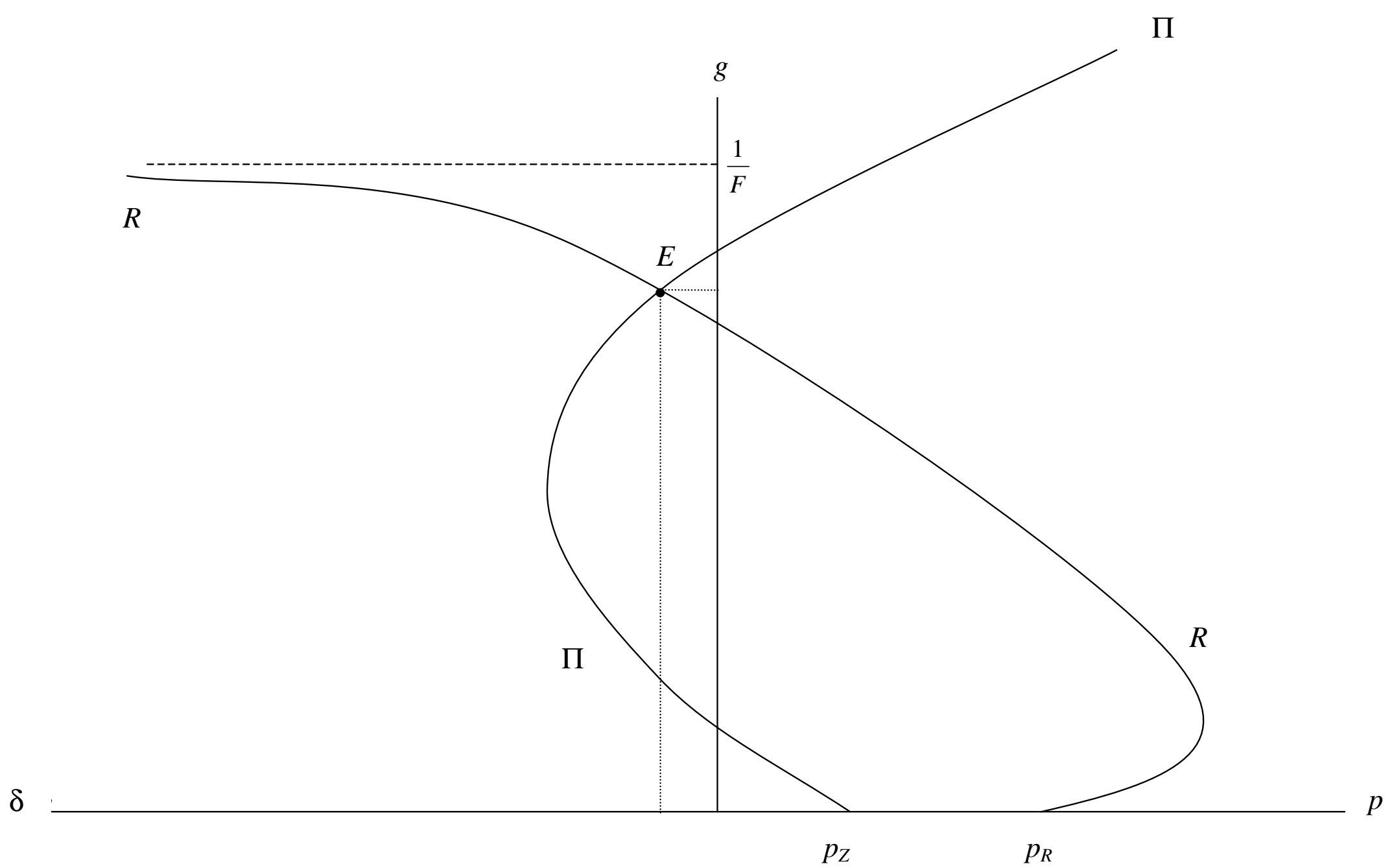


Figure 2: The Engel-curve for good $i=N(t)$

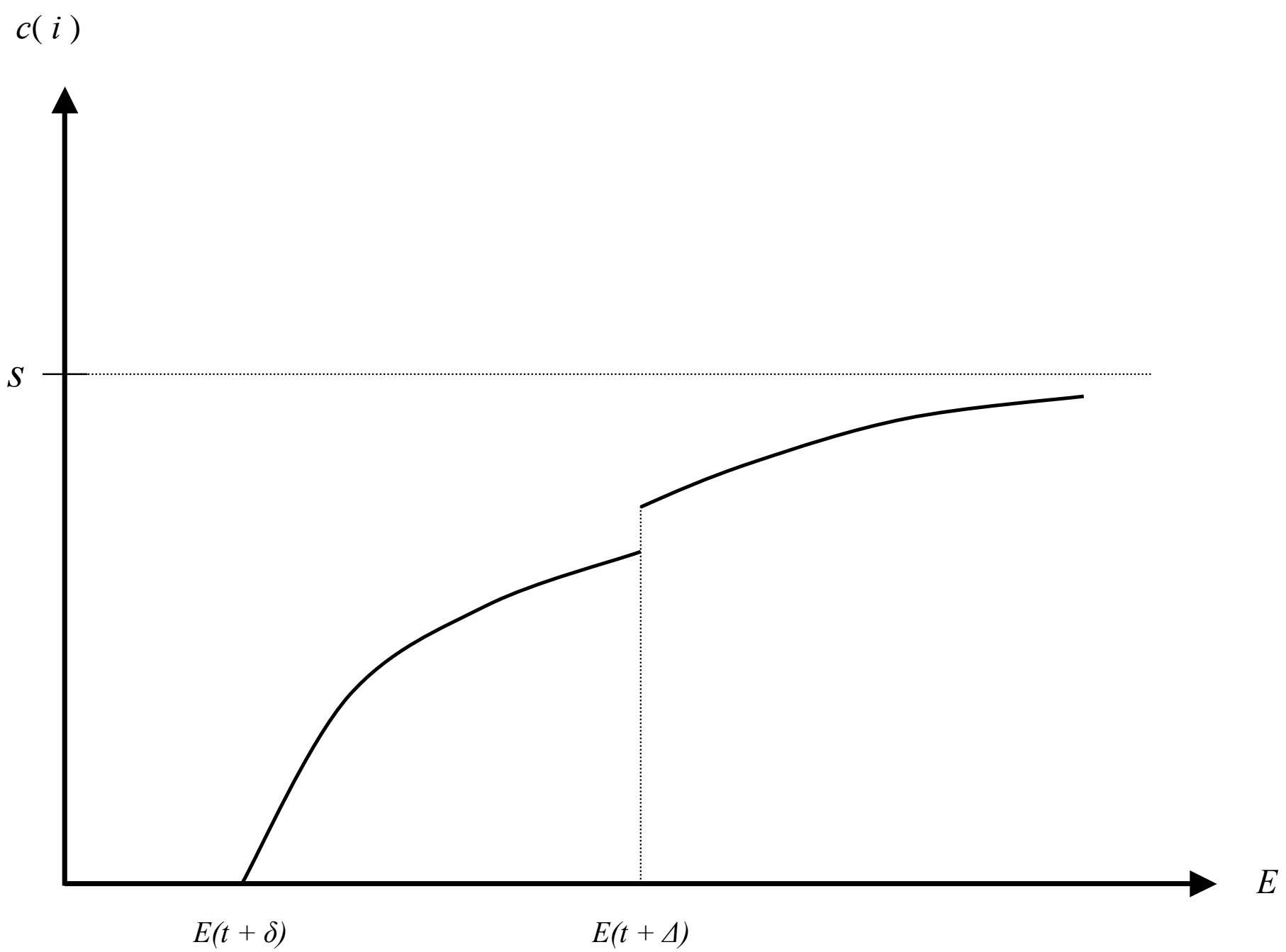




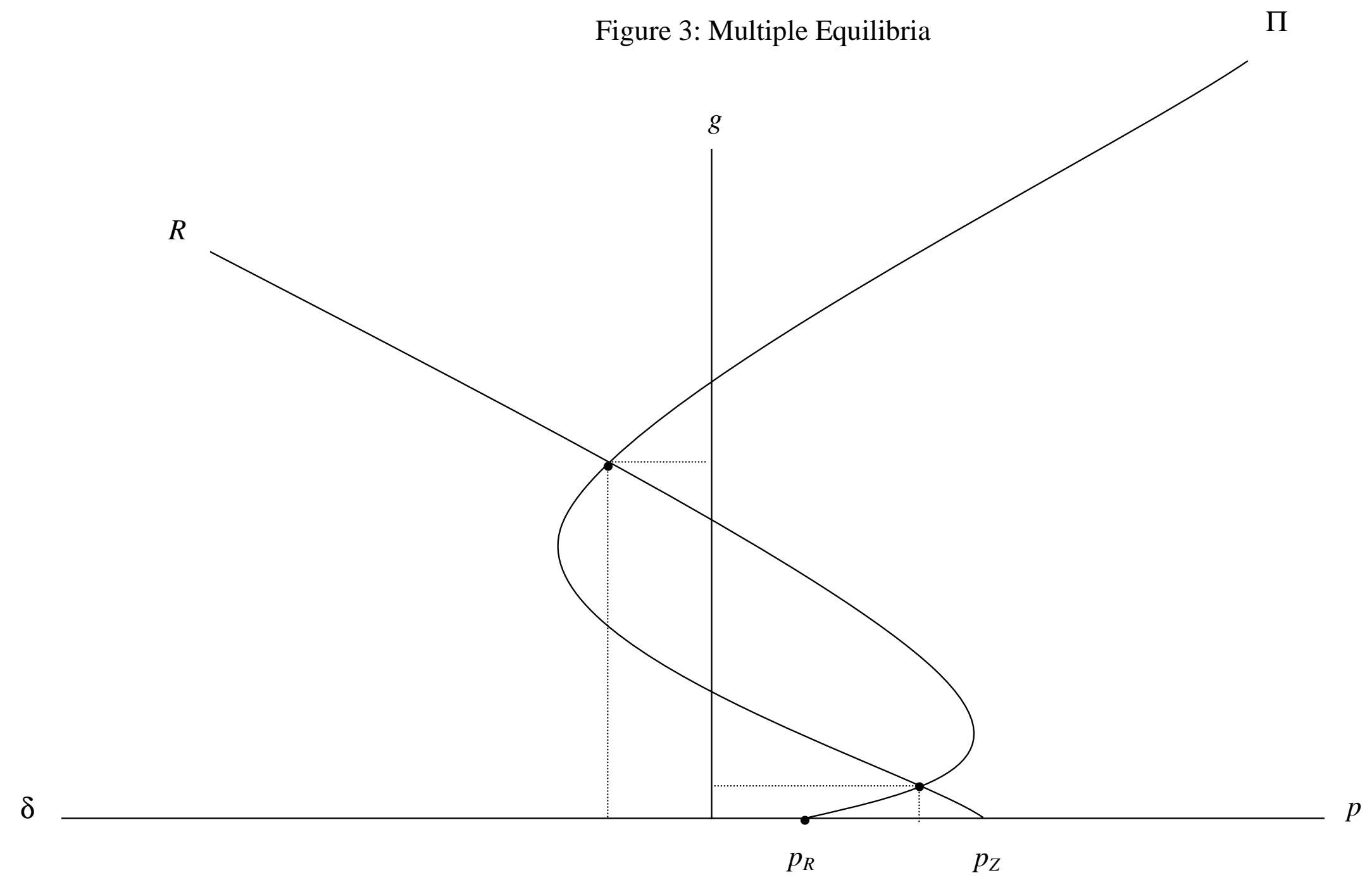


Figure 4: Reallocation of Labor Across Sectors

Default Parameter values:

$$
\sigma=2 \quad \rho=0.02 \quad F=8 \quad L=1 \quad \Delta=\infty \quad b s=10 / 3 \quad \gamma=0.77
$$
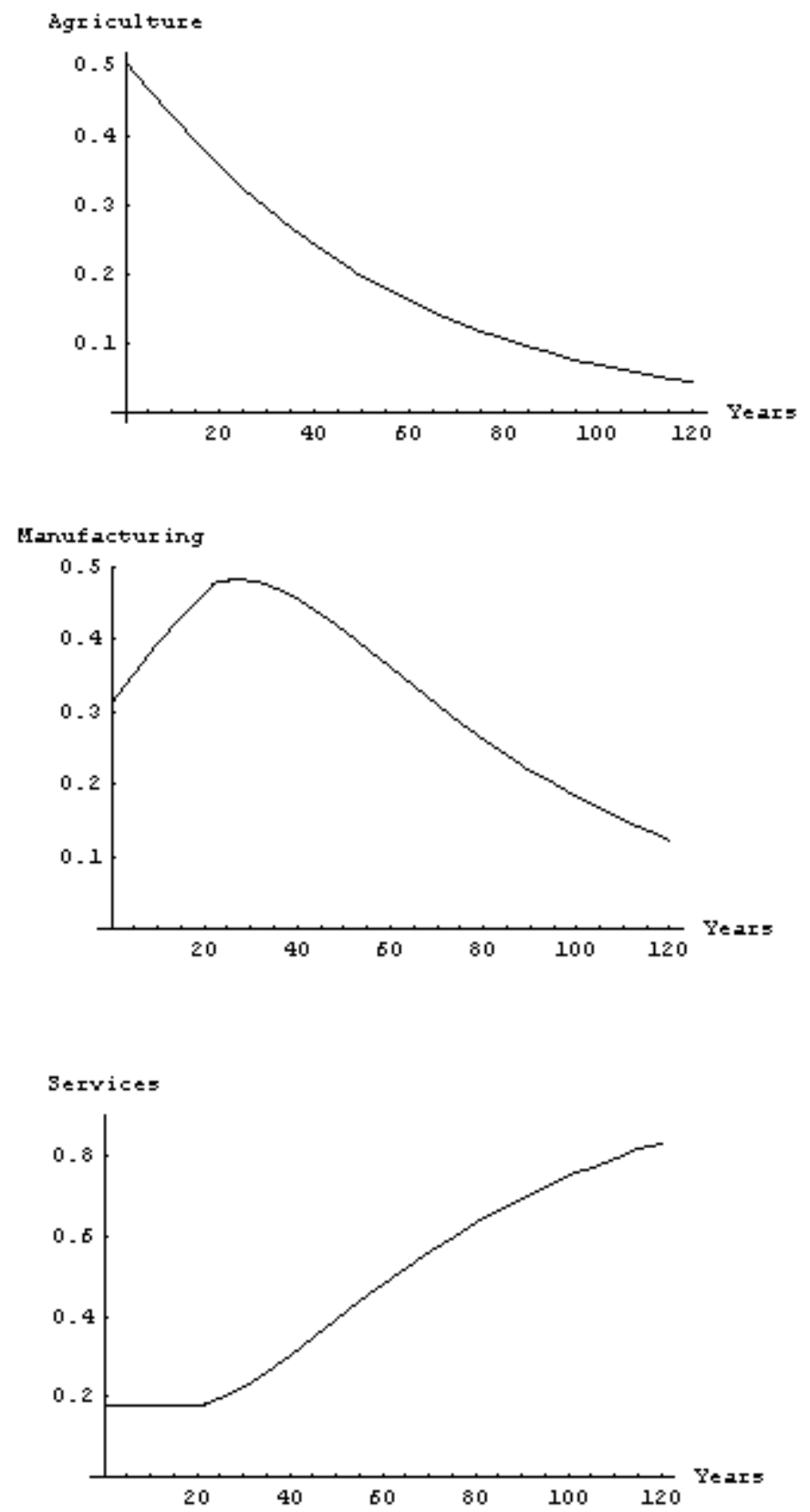